University of South Florida

DIGITAL COMMONS

Digital Commons @ University of

@ UNIVERSITY OF SOUTH FLORIDA

South Florida

USF Tampa Graduate Theses and Dissertations

USF Graduate Theses and Dissertations

November 2018

\title{
Simulation and Optimization of a Sheathless Size-Based Acoustic Particle Separator
}

Shivaraman Asoda

University of South Florida, a.shivaraman@gmail.com

Follow this and additional works at: https://digitalcommons.usf.edu/etd

Part of the Mechanical Engineering Commons

\section{Scholar Commons Citation}

Asoda, Shivaraman, "Simulation and Optimization of a Sheathless Size-Based Acoustic Particle Separator" (2018). USF Tampa Graduate Theses and Dissertations.

https://digitalcommons.usf.edu/etd/8103

This Thesis is brought to you for free and open access by the USF Graduate Theses and Dissertations at Digital Commons @ University of South Florida. It has been accepted for inclusion in USF Tampa Graduate Theses and Dissertations by an authorized administrator of Digital Commons @ University of South Florida. For more information, please contact digitalcommons@usf.edu. 
Simulation and Optimization of a Sheathless Size-Based Acoustic Particle Separator

by

Shivaraman Asoda

\begin{abstract}
A thesis submitted in partial fulfillment of the requirements for the degree of Master of Science in Mechanical Engineering

Department of Mechanical Engineering College of Engineering University of South Florida
Major Professor: Rasim Guldiken, Ph.D. Andres Tejada-Martinez, Ph.D. David W. Murphy, Ph.D.

Date of Approval:

October 12, 2018

Keywords: Separation Efficiency, Acoustic Radiation Force, Standing Surface Acoustic Wave, Microfluidics

Copyright ( 2018, Shivaraman Asoda 


\section{DEDICATION}

I dedicate this work to everyone who has been there to support me and contributed to the success of this Thesis. I also dedicate this work to my parents, Kumara Swamy and Krishnaveni, and to my grandfather Komuraiah, who gave me an opportunity to pursue my master's. 


\section{ACKNOWLEDGMENTS}

I would like to acknowledge and thank the following important people who have supported me, not only during the course of this project, but throughout my master's degree.

Firstly, I would like to express my gratitude to Dr. Rasim Guldiken, for his expertise, assistance and patience throughout the process of writing this thesis. Without your help this project would not have been possible. I would like to thank my committee members, Dr. Andres TejadaMartinez and Dr. David W. Murphy for their support and helpful suggestions which helped me to finish this project. Finally, I would like to thank my family, who have supported me during graduate degree. 


\section{TABLE OF CONTENTS}

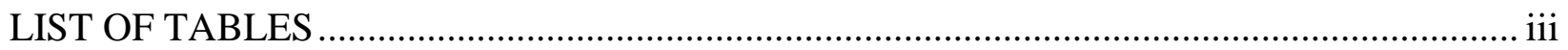

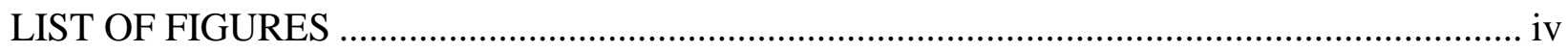

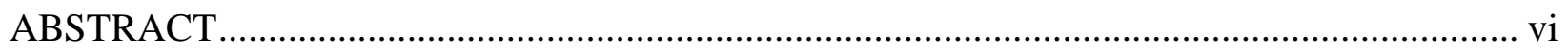

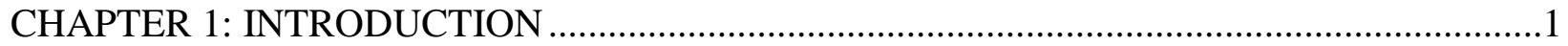

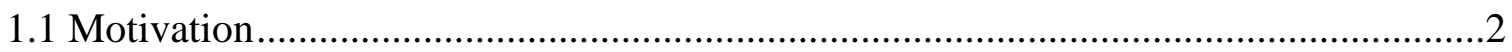

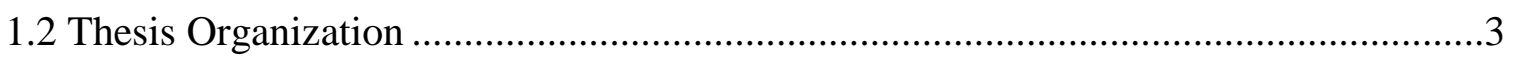

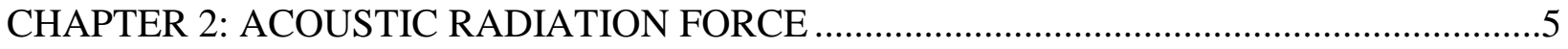

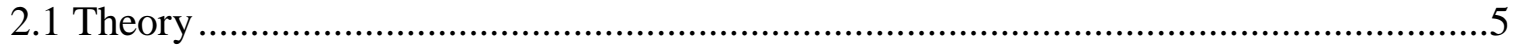

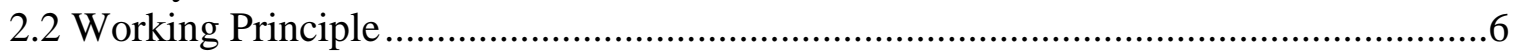

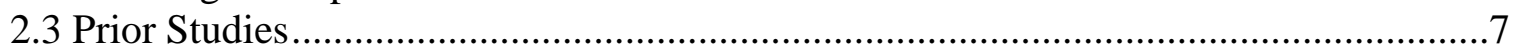

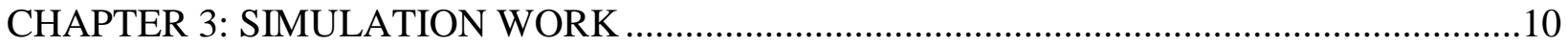

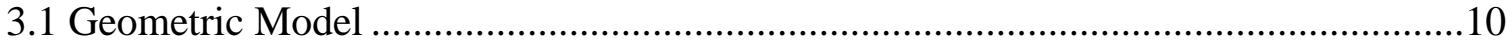

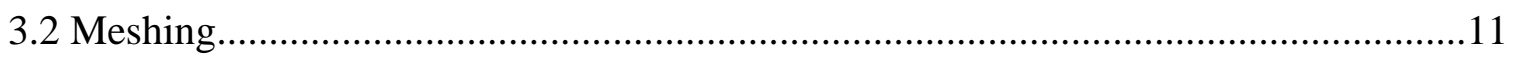

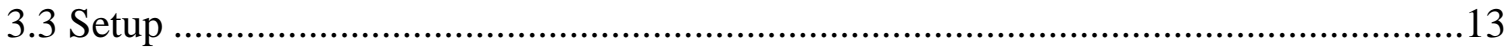

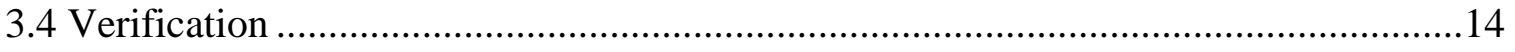

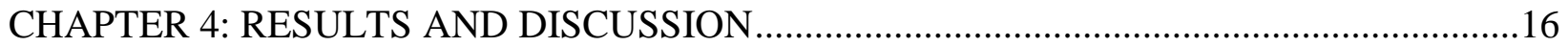

4.1 Separation of $10 \mu \mathrm{m}$ and $3 \mu \mathrm{m}$ Particles ................................................................16

4.2 Critical Particle Size for Acoustic Particle Separation with $3 \mu \mathrm{m}$ Particles .................19

4.3 Effect of Flow Rate on Separation Efficiency …………..............................................20

4.4 Effect of Interdigital Transducer (IDT) Length on Separation Efficiency ……...........25

4.5 Effect of Transducer Wavelength on Separation Efficiency …………………….......28

4.6 Effect of Separator Offset on Efficiency ...................................................................30

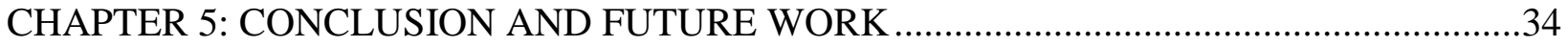

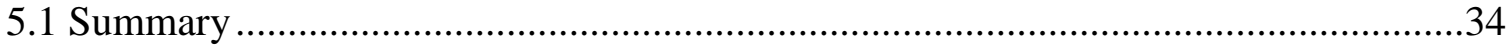

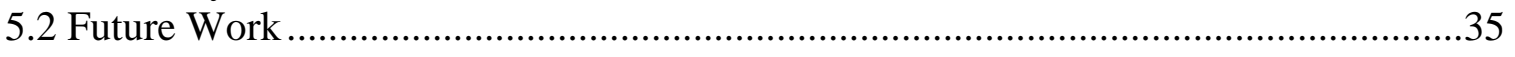

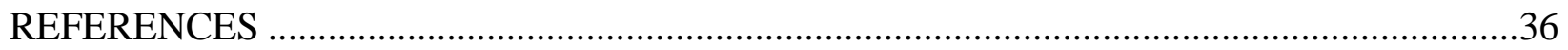

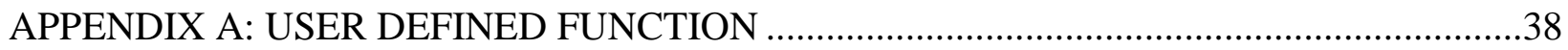

A.1 Acoustic Radiation Force ……………………….....................................................38

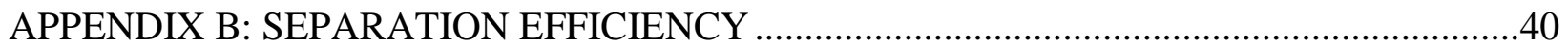


APPENDIX C: COPYRIGHT PERMISSIONS 


\section{LIST OF TABLES}

Table 1. Mesh metrics for the designed model ......................................................................13

Table 2. Ideal parameter values for $3 \mu \mathrm{m}$ and $6 \mu \mathrm{m}$ particles separation ....................................34 


\section{LIST OF FIGURES}

Figure 1. (a) Fabricated IDTs patterned on a lithium niobate wafer; (b) microchannel mold;

(c) acoustic particle separator

Figure 2. Conceptual view of SSAW particle separator ....................................................8

Figure 3. Microfluidic channel of SSAW particle separator (dimensions in millimeter).............10

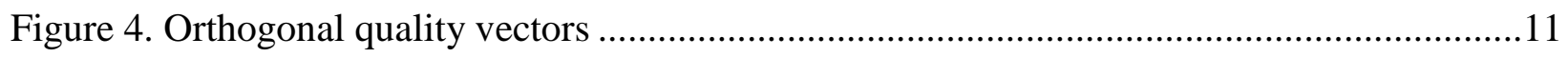

Figure 5. Time taken for particles to reach pressure node ......................................................15

Figure 6. The chosen location (I, II) and outlets (A-C) in the microchannel for capturing the distribution of particles .......................................................................... 16

Figure 7. Variation of separation efficiency with second stage pressure amplitude ...................17

Figure 8. Variation of separation efficiency with first stage pressure amplitude .......................18

Figure 9. Variation of separation efficiency with second stage pressure amplitude ...................19

Figure 10. Variation of separation efficiency with pressure amplitude (II) .............................20

Figure 11. Separation efficiency as a function of flow rate ..............................................21

Figure 12a. Particle tracks of $3 \mu \mathrm{m}$ (green) and $6 \mu \mathrm{m}$ (red) particles at $8.33 \mathrm{e}-09 \mathrm{~kg} / \mathrm{s}$ flowrate

Figure 12b. Particle tracks of $3 \mu \mathrm{m}$ (green) and $6 \mu \mathrm{m}$ (red) particles at $1.67 \mathrm{e}-08 \mathrm{~kg} / \mathrm{s}$ flowrate

Figure 13a. Particle tracks of $3 \mu \mathrm{m}$ (green) particles at $1.67 \mathrm{e}-08 \mathrm{~kg} / \mathrm{s}$ flowrate.........................23

Figure 13b. Particle tracks of $3 \mu \mathrm{m}$ (green) particles at $8.33 \mathrm{e}-08 \mathrm{~kg} / \mathrm{s}$ flowrate.........................23

Figure 14a. Particle tracks of $6 \mu \mathrm{m}$ (red) particles at 3.33e-08 kg/s flowrate ...........................24

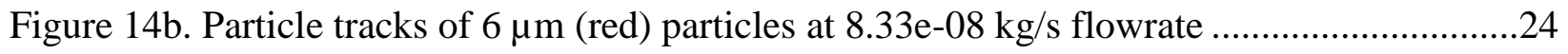

Figure 15. Separation efficiency as a function of first stage IDTs length ...............................25 
Figure 16a. Particle tracks of $6 \mu \mathrm{m}$ (red) particles at $5.7 \mathrm{~mm}$ first stage IDTs length

Figure 16b. Particle tracks of $6 \mu \mathrm{m}$ (red) particles $9.7 \mathrm{~mm}$ first stage IDTs length .27

Figure 17. Separation efficiency as a function of second stage IDTs length.

Figure 18. Separation efficiency as a function of first stage wavelength .28

Figure 19. Variation in ARF with particle position (y) for different wavelengths

Figure 20. Separation efficiency as a function of second stage wavelength .30

Figure 21. Offset $(\Delta y)$ due to misalignment between microchannel and IDT's .31

Figure 22. Separation efficiency as a function of offset $(\Delta y)$ 31

Figure 23a. Tracks of $6 \mu \mathrm{m}$ particles (red) at $1 \mu \mathrm{m}$ offset .32

Figure $23 \mathrm{~b}$. Tracks of $6 \mu \mathrm{m}$ particles $(\mu \mathrm{m})$ at $3 \mu \mathrm{m}$ offset..... .32 


\begin{abstract}
${ }^{1}$
Standing surface acoustic waves (SSAW) have been widely used for sorting of cells and particles. However, the major challenges faced with the acoustic driven separation process is the need for an optimized setup to achieve effective separation and the range of particles that can be separated. In this thesis, a custom simulation model is studied to investigate and optimize the separation of varying size particles in a sheathless acoustic separation platform that was developed in our research lab. Specifically, the effect of flowrate, pressure amplitude, wavelength and interdigitated transducers (IDTs) physical parameters on the separation efficiency is explored. We also explored the critical particle size for acoustic particle separation with $3 \mu \mathrm{m}$ particles and demonstrated, successful $3 \mu \mathrm{m}$ and $6 \mu \mathrm{m}$ particles for the first time for this sheathless separation platform. The ANSYS® FLUENT was utilized to numerically simulate acoustic radiation force (ARF) on the particles for separation. With the increase in the pressure amplitude in the first and second stage to $80 \mathrm{kPa}$ and $110 \mathrm{kPa}$ respectively, the optimization studies presented have shown to improve the separation efficiency of the model over $96 \%$ for both $10 \& 3 \mu \mathrm{m}$ particles. Findings of the current study will aid in increasing the efficiency of particle separation and in designing the SSAW driven microfluidic devices.
\end{abstract}

\footnotetext{
${ }^{1}$ Portions of this thesis have been previously published in the Microsystem Technologies, 2018. Permission from Springer Nature to reproduce is included in Appendix C.
} 


\section{CHAPTER 1: INTRODUCTION}

Isolating specific cells is a crucial step in many techniques used in the area of biology and related disciplines. In biomedical applications, effective cell sorting is required for understanding the cells function and their response to stimuli [1]. Use of sorted cells reduces the heterogeneity of the study sample and decreases the variations among the experiments. Some of the representative examples in biomedicine where separation techniques employed are: sorting out malaria infected cells for diagnostics, isolation of platelets and separation of circulating tumor cells from the blood [1-4].

Numerous sorting techniques have been developed based upon the physical properties of the cell such as size, density, electrical or magnetic affinity etc. [1,3]. Standard separation methods such as filtration, centrifugation and sedimentation can be used for the separation of cells [1]. In cases where the cell size or density difference are not significant, the efficiency of the cell separation is lower. In such cases, acoustic based cell separation techniques may be employed to acquire higher cell sorting efficiency.

In acoustic based cell separation technique, microfluidic separation is accomplished by applying differential forces on cells to guide them into various paths. This is the only active separation method that can distinguish cells based on their density, compressibility and size [5]. As this method requires the application of external acoustic forces the efficiency of the device can be controlled to accommodate the sorting of cell samples with distinct physical properties [6]. Compared to other standard cell sorting techniques, acoustic-based manipulations have been recognized as more biocompatible [7]. Acoustic based approaches thus offer excellent alternatives 
for cell separation and have potential to aid in cancer research, therapeutics and drug efficacy assessment [5]. Further acoustic particle separation techniques find use in many industrial applications for the separation of solid particles present in air [8].

In this work, we present an advanced simulation study of cell sorting technique that is based on a tunable standing surface acoustic waves (SSAW). In SSAW-based cell separation, cells experience acoustic radiation force (ARF) directly instead of using the acoustic streaming effect which manipulate the fluids in the microchannel [9]. This process can define and modify the position of pressure nodes (PNs) and consequently guide the cells into different paths (and into the designated outlets). This method can accomplish more controlled and stable cell separation when compared to acoustic-streaming-based methods which is often unpredictable [9]. In addition, this method can produce a large translation and it is capable of separating cells into a great number of outlet channel (e.g. four) in a single step [9]. This provides a significant advantage over many existing cell-separation methods, which typically separate the cells into two outlets. However, for efficient separation, positioning of the PNs/ANs (pressure anti nodes) is required depending upon the design of the microchannel. This can be achieved through the generation of tunable SSAW using interdigital transducers (IDTs). Hence, by tuning the frequency of SSAW, we can adjust the position of PNs/ANs in the lateral direction normal to the cell flow, which in turn drives the cells to their designated outlets [9].

\subsection{Motivation}

The motivation behind this study is the need for development of a model that can simulate particles of various physical properties in the presence of SSAW and explore for the ways to increase separation efficiency. 
Simulation is a powerful tool that can be utilized to mimic the behavior of a phenomenon for analyzing and solving related potential problems. Despite the complications involved in the development of the model, simulations are preferred over the real-world experiments as it gives insights into the behaviors of a system without actually building it. In addition, simulations are less time consuming and can be used for the verification of analytical solutions. This makes simulation a plausible alternate to the real-world experiments.

In this study, we developed a simulation model that demonstrates particle separation by ARF and has the ability to simulate the particles of different physical properties. We also performed systematic parametric studies of the factors influencing the separation efficiency of the model and explore the merits of utilizing alternate designs to optimize the separation efficiency. Although this study concentrates on the separation of polystyrene particle, it can also be extended for particles of any type.

\subsection{Thesis Organization}

This thesis is organized in the following manner

1 Chapter 2: This section will discuss the theoretical background on acoustic radiation force on compressible sphere. This chapter will also discuss the previous work that has been done in standing surface acoustic wave (SSAW) based separation.

2 Chapter 3: This section will give the specifics of the design selected for the study. It will also cover other important aspects such as meshing, and background conditions considered for the simulation.

3 Chapter 4: This chapter will concentrate on the separation efficiency of the model and will discuss the ways to optimize it. 
4 Chapter 5: This section will present the conclusions drawn from the investigations and the potential future works that it can be reached out to. 


\section{CHAPTER 2: ACOUSTIC RADIATION FORCE ${ }^{2}$}

This section will discuss the theoretical background on acoustic radiation force on compressible sphere. This chapter will also discuss the previous work that has been done in standing surface acoustic wave (SSAW) based separation.

The radiation force experienced by an object in the presence of acoustic field is known as acoustic radiation force (ARF) [10]. Acoustic radiation force can be used to manipulate the particle trajectories by moving them towards the nodal (or anti-nodal) positions in an acoustic field depending upon their material properties. Utilizing this principle, various acoustic based separators have been investigated for biomedical and chemical analysis. For generating acoustic standing wave field, either bulk acoustic waves (BAWs) or surface acoustic waves (SAWs) can be used in microfluidic devices [11]. In this study we adopt a method of using SSAW for continuous particle separation in a microfluidic channel. Using this method, particles present in the fluid medium can be separated based on their compressibility, density and volume [12].

\subsection{Theory}

The investigation of acoustic radiation force on suspended particles has a long history. The analysis of acoustic radiation force on incompressible spheres was done by King in 1934 [13], while the forces on compressible spheres were calculated by Yosioka and Kawasima in 1955 [14]. ARF (Fr) induced on a particle present in an acoustic standing wave field in a compressible medium is given by [14]

\footnotetext{
${ }^{2}$ Portions of this chapter have been previously published in The Sensors (Basel). 2012. Permission is included in Appendix C.
} 


$$
\begin{gathered}
\mathrm{F}_{\mathrm{r}}=-\frac{\left(\pi p_{o}{ }^{2} V \beta_{m}\right)}{2 \lambda} \varphi(\beta, \rho) \sin (2 k x) \\
\varphi(\beta, \rho)=\frac{\left(5 \rho_{p}-2 \rho_{m}\right)}{\left(2 \rho_{p}+\rho_{m}\right)}-\frac{\beta_{p}}{\beta_{m}}
\end{gathered}
$$

where $\beta, \lambda, \rho, V$ are the particle's compressibility, wavelength, density, volume while $k, x, p_{o}, \varphi$ are the wavenumber, distance from the pressure node, acoustic pressure amplitude and acoustic contrast factor respectively. The subscript of $m$ and $p$ represent the liquid medium and particle respectively.

From equation 1, it can be observed that the ARF changes sinusoidally with an interval of a half wavelength in space. The displacement of the particle towards the pressure node or the pressure anti-node is determined by the acoustic contrast factor $(\varphi)$ : if $\varphi>0$, the particles will gather at pressure nodes; if $\varphi<0$, the particles will gather at antinodes [15]. It is noted that the force on a particle is directly proportional to the cube of particle radius and this indicates that the larger particles will experience higher force than the smaller particles.

\subsection{Working Principle}

The SSAW generator consists of a pair of interdigitated transducers (IDTs) fabricated on a piezoelectric substrate. A microchannel is set between two IDTs to form a microfluidic device. Application of AC signal to the IDT's causes the SAWs to propagate in the opposite direction towards the microchannel. Constructive interference of the two SAWs leads to the formation of SSAW field across the channel. The SSAW couples into the fluid medium and produces acoustic radiation force on the particles present in the liquid. The change in the trajectory of a particle towards PNs or ANs is determined by the compressibility and the density of the particle and the surrounding medium. However, most solid particles suspended in aqueous solution, including cells move towards the pressure nodes [15]. 


\subsection{Prior Studies}

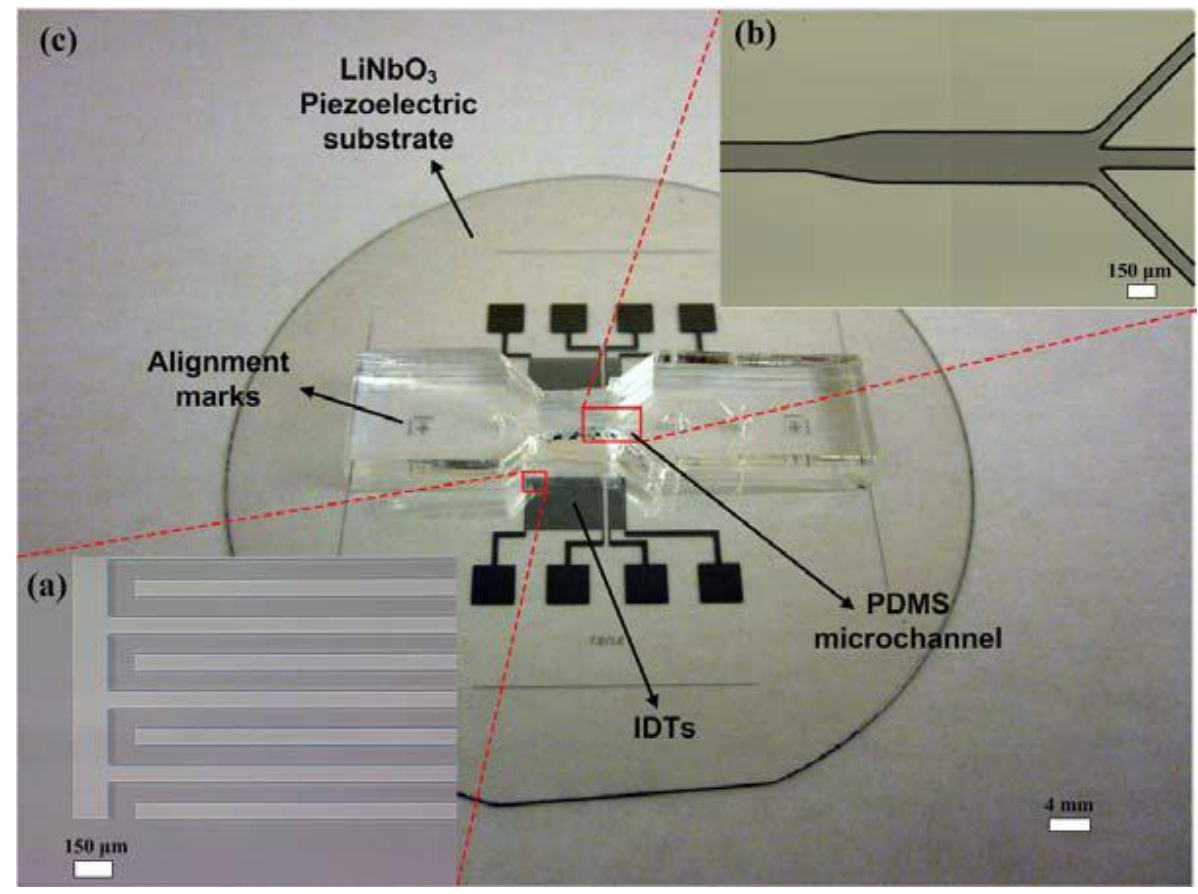

Figure 1. (a) Fabricated IDTs patterned on a lithium niobate wafer; (b) microchannel mold; (c) acoustic particle separator [2].

The simulation work performed in this study is based on a sheathless size-based acoustic particle separation design that was experimentally investigated previously [2]. In the exploratory work carried out, four IDTs with a rectangular component design are utilized to generate acoustic standing wave fields. The IDT finger width and finger pitch were picked as $75 \mu \mathrm{m}$ and $300 \mu \mathrm{m}$ respectively. A pair of IDTs of sizes $7.7 \mathrm{~mm} \times 6 \mathrm{~mm}$ and $1.7 \mathrm{~mm} \times 6 \mathrm{~mm}$ were fabricated on lithium niobite substrate in the first stage and second stage respectively as shown in Figure 1.

The microchannel is fabricated on the substrate such that it is located on the center line between the IDTs and the SAW wavelength was chosen to be $300 \mu \mathrm{m}$. Figure 2 illustrates the design concept of a two-stage SSAW particle separator. For the first stage, the width of the microchannel has been designed to be equivalent to half of the wavelength of the SSAW. The design promotes the aggregation of the particles at the micro-channel centerline, before they enter 
the second stage. In order to have the two off-center pressure nodes, the second stage microchannel width was taken to be that of one full wavelength. As the particles travel in the second stage of the design across the microchannel, acoustic forces are experienced by the particles towards the pressure nodes. Depending on the material properties, the unlike particles experience different acoustic forces leading them to follow different trajectories. Therefore, variation in material properties of these particles results in their subsequent segregation.

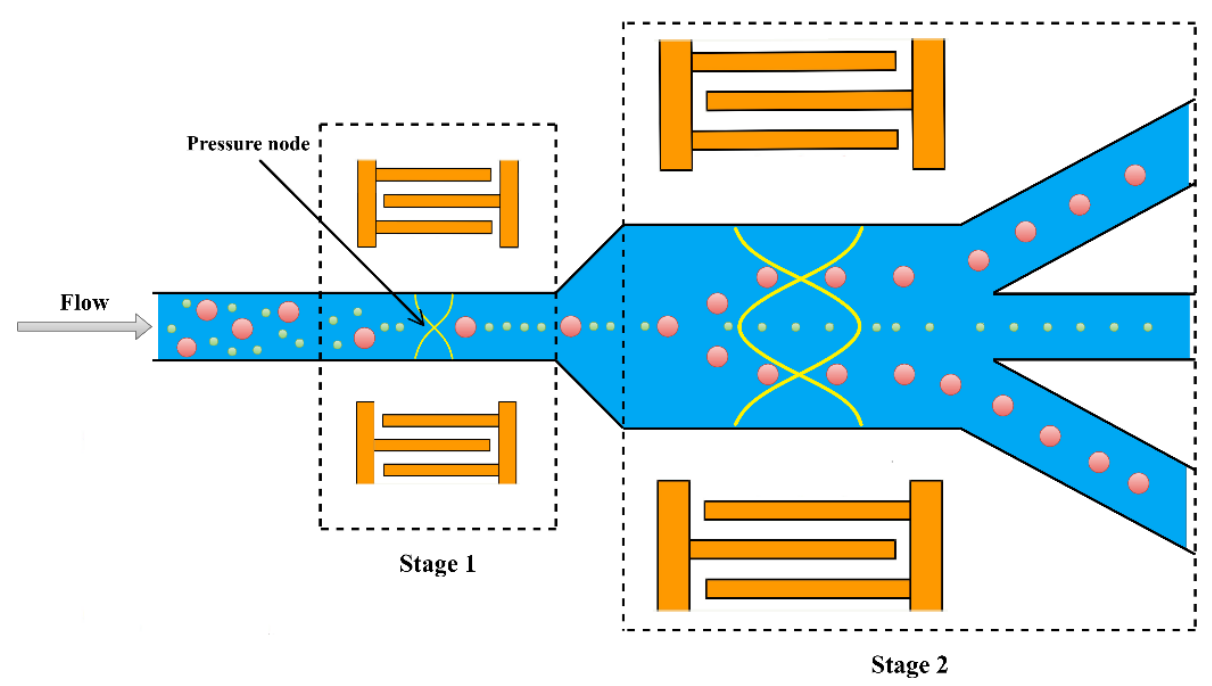

Figure 2. Conceptual view of SSAW particle separator.

The solution mixture used for separation involved polystyrene fluorescent particles $(\beta=$ $2.46 \mathrm{e}-10 \mathrm{~Pa}-1$ and $\rho=1.05 \mathrm{~g} / \mathrm{cm} 3$ ) with diameter $3 \mu \mathrm{m}$ and $10 \mu \mathrm{m}$ and were infused into the microchannel by a syringe pump. The acquired highspeed images of the fluorescence in the microchannel were used to observe the particle segregation in the acoustic standing wave fields in DI-water medium $(\beta=4.58 \mathrm{e}-10 \mathrm{~Pa}-1$ and $\rho=1.0 \mathrm{~g} / \mathrm{cm} 3)$. From the experimental measurements, it was observed that the fluorescent particles in the DI-water medium were effectively isolated with high efficiency and the sheathless SSAW based particle separation has been accomplished.

The present work is performed to further support the experimental data by using numerical simulations. A commercially available finite element modeling software - ANSYS® Fluent - is 
used to simulate particle velocity distribution, acoustic radiation force and particle patterning process. The present study not only considers the separation of same particles of two different sizes, but also examines the merits of utilizing alternate designs to optimize the separation efficiency. 


\section{CHAPTER 3: SIMULATION WORK ${ }^{3}$}

Recent developments in the field of numerical simulation enabled Computational Fluid Dynamics (CFD) an effective method to reveal the properties of the fluid flow. They provide fast and flexible methods for solving engineering problems at low cost. These numerical simulations are based on solving Navier-Stokes flow equations approximately. OpenFOAM®, COMSOL Multiphysics ${ }^{\circledR}$ and ANSYS ${ }^{\circledR}$ Fluent are some of the CFD packages that are available for solving these equations. Incorporating the simulations in biomedicine has led to the better understanding of various phenomena like blood flow in deformable vessels [16], assessing the growth rate of tumors [17] etc. As a result, the application of CFD in biomedicine industry have gradually increased over the past few years. In this study, the commercial software ANSYS® 18.1 was used for designing and simulating the fluid flow in the microchannel.

\subsection{Geometric Model}

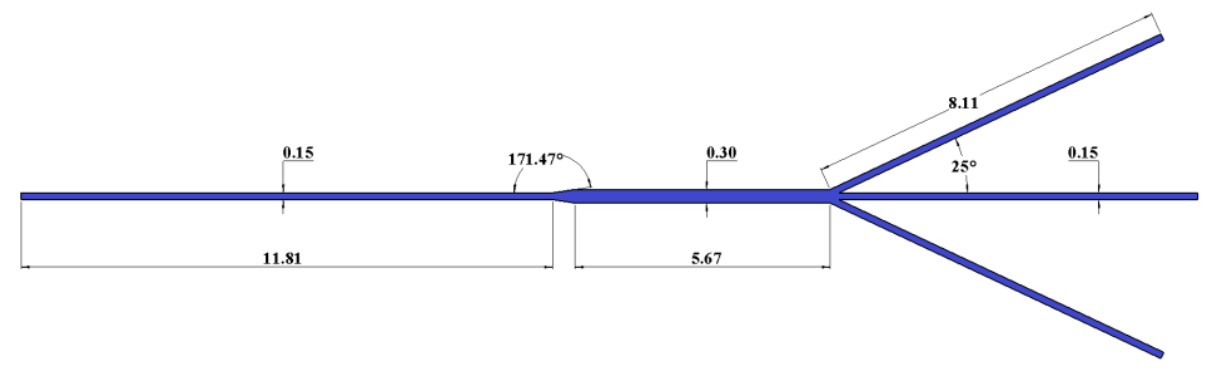

Figure 3. Microfluidic channel of SSAW particle separator (dimensions in millimeter).

${ }^{3}$ Portions of this chapter have been previously published in Ansys ${ }^{\circledR}$ Acadamic Research. Release 18.1 ed. Permission is included in Appendix C. 
Based on the concept of a two-stage SSAW particle separator, a geometric model illustrated in Figure 3 was established by using ANSYS DesignModeler. The length of the first microchannel and second microchannel are $11.81 \mathrm{~mm}(0.46 \mathrm{in})$ and $5.67 \mathrm{~mm}(0.22 \mathrm{in})$ respectively. The model has a single inlet and three outlets. The first channel has a width of $0.15 \mathrm{~mm}(0.006 \mathrm{in})$ and the second stage microchannel width is taken as $0.3 \mathrm{~mm}(0.012 \mathrm{in})$. The depth of the channel is $0.1 \mathrm{~mm}(0.004 \mathrm{in})$ and is maintained uniform throughout the flow.

\subsection{Meshing}

Meshing phase is an important stage in performing numerical simulations. Increase in mesh quality can reduce discretization error significantly and ensure the best results for a given problem. In ANSYS the mesh quality is analyzed through mesh quality metrics which include: orthogonality, aspect ratio and skewness.

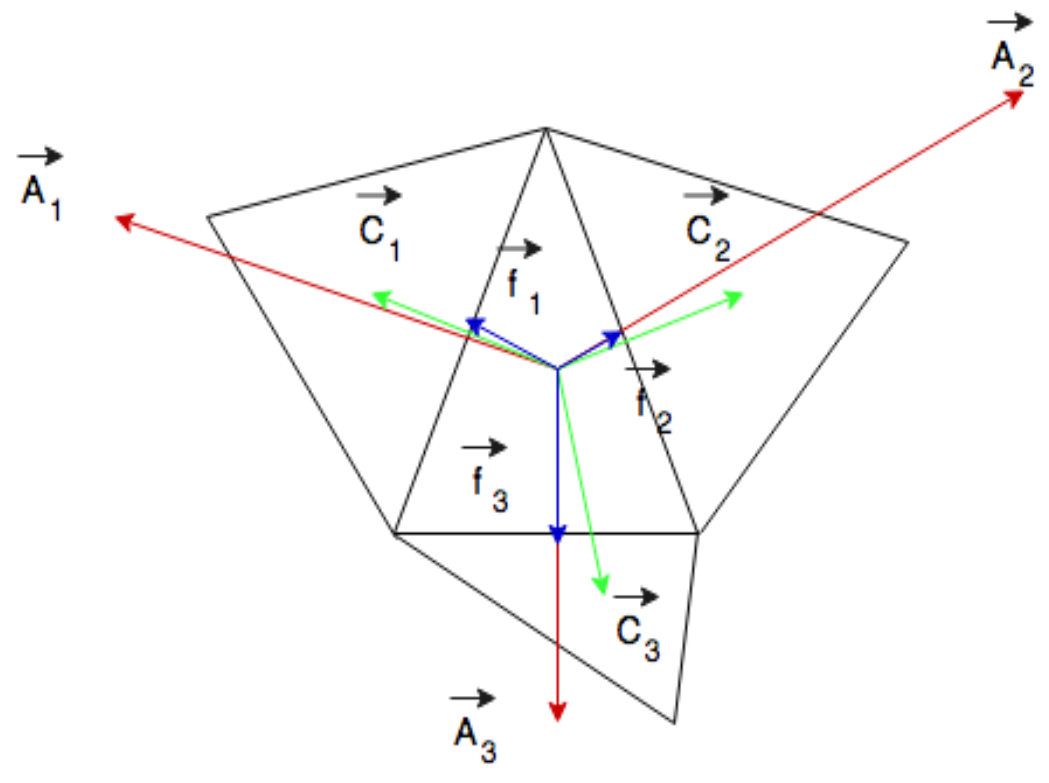

Figure 4. Orthogonal quality vectors.

Orthogonal quality for a cell is defined as the minimum value of the equations (3) and (4) computed for each face [18]. 


$$
\begin{aligned}
& \text { Orthogonal quality }=\frac{\vec{A}_{i} \cdot \vec{f}_{i}}{\left|\vec{A}_{i}\right|\left|\vec{f}_{i}\right|} \\
& \text { Orthogonal quality }=\frac{\vec{A}_{i} \cdot \vec{C}_{i}}{\left|\vec{A}_{i}\right|\left|\vec{C}_{i}\right|}
\end{aligned}
$$

where $\vec{A}_{i}$ is the face normal vector, $\vec{f}_{i}$ is the vector from the centroid of the cell to the centroid to that face and $\vec{C}_{i}$ is a vector from the centroid of the cell to the centroid of the adjacent cell as represented in the Figure 4. The orthogonal quality for a mesh varies on the scale of 0 to 1 , with 0 being the least and 1 being the most effective [18].

The second mesh metric, aspect ratio of a cell is defined as the ratio of maximum to minimum distance from the centroid of the cell to the nodes and centroids of the face respectively [18]. Skewness, the third quality metric, analyses and compares the shape of the cell to the shape of an equilateral cell of equivalent volume with respect to its angles or volume [18].

In this study, mesh for the simulation model is generated by performing edge sizing along the length, width and height of the model. As a result, the generated mesh contains of 125048 nodes and 98490 elements. ANSYS specifies that an orthogonal quality of 0.95 and skewness less than 0.25 are considered excellent [18]. For the model designed, the average orthogonal quality and the average skewness of the cells generated are 0.99306 and $4.6509 \mathrm{e}-002$, respectively as illustrated in Table 1. The maximum aspect ratio of the mesh is 7.5323 which is within the acceptable limits, as the ANSYS guide specifies that the quadrilateral/hexahedral/wedge cells inside the boundary layer can have the aspect ratio of up to 10:1 in most cases. With regard to the stability of the flow solution, aspect ratio can go as high as possible. However, the maximum aspect ratio should be kept below 35:1 [18]. 
Table 1. Mesh metrics for the designed model.

\begin{tabular}{|c|c|c|}
\hline Mesh metric & Obtained & Ideal range \\
\hline Orthogonal quality & 0.99306 & $0.95-1$ \\
\hline Aspect ratio & 7.5323 & $<10$ \\
\hline Skewness & $4.6509 \mathrm{e}-02$ & $>0-0.25$ \\
\hline
\end{tabular}

\subsection{Setup}

An Ansys fluent model was developed based upon the boundary conditions as observed from the experimental setup of the sheathless size based acoustic particle separation [2]. For all the cases analyzed, A laminar viscous model with fluid as DI-water medium $(\rho=1.0 \mathrm{~g} / \mathrm{cm} 3)$ and particles as polyester fluorescent particles $(\rho=1.05 \mathrm{~g} / \mathrm{cm} 3)$ were used for performing the separation. The boundary conditions have been derived from the experimental setup. An experimental average inlet mass flow rate of $8.33 \mathrm{e}-09 \mathrm{~kg} / \mathrm{s}$ was taken as inlet boundary condition while the outlet gauge pressure has been taken to be $0 \mathrm{KPa}$. Reynold's number at the inlet has been calculated using the equation (5) and it has been found to be equal to 0.075 . The hydraulic diameter for the inlet was $1.2 \mathrm{e}-04$.

$$
R e=\frac{\rho \mathrm{u} D_{h}}{\mu}
$$

where $D_{h}$ is the hydraulic diameter, $\mathrm{u}$ is the velocity, $\rho$ is the density and $\mu$ is the dynamic viscosity of the fluid.

In discrete phase modelling, surface type injection was selected at the inlet for introducing the particles into the fluid and face normal direction was used as the boundary condition. The body 
force experienced by the particles due to the acoustic radiation force, during their flow has been applied through a user defined function in discrete phase modeling [Ref. A.1]. The simulation is then carried out for particles of different diameters by varying different parameters.

After the simulation, a step by step report of each injection was extracted from particle tracks with reporting variables as Particle Residence Time, Particle I.D, Particle Y Position, Particle X position and Particle Time step in order [Ref. B]. The data obtained from the track history is then used as an input to a developed code to calculate the number of particles obtained at each outlet [Ref. B]. The separation efficiency for the simulation is then calculated depending upon the number of particles at their respective outlets. To quantitatively evaluate the accuracy of the simulation, the time taken by the particles to reach to the pressure nodes in the first stage was compared and verified with the theoretical data.

\subsection{Verification}

When a particle in the SSAW field maintains a constant velocity, the time needed for its migration towards the respective pressure node which is at a distance $\delta x$ in the range of $(0, \lambda / 4)$ is given by the expression [12].

$$
t=\left(\frac{3 \lambda^{2} \eta r_{c}}{\pi}\right)\left[\ln \tan \left(\frac{2 \pi x}{\lambda}\right)\right]_{x_{1}}^{x_{2}} /\left[p_{o}^{2} V_{c} \beta_{w} \emptyset(\rho, \beta)\right]
$$

where $\lambda, \varnothing, \eta, \beta_{w}$ correspond to wavelength, viscosity, acoustic contrast factor, viscosity, compressibility of the medium respectively and $p_{o}, r_{c}, V_{c}$ correspond to pressure amplitude, particle radius and particle volume respectively.

For verification purposes, 16 particles having particle id's 0 to 15 were chosen from Fluent. These 16 particles were found to be randomly oriented around the center of the channel. Then the time taken for the particles to reach the pressure node in the first stage is estimated from the Fluent track history file. The results from the simulation is then compared with the theoretical data 
obtained from the Equation (6). Figure 5 illustrates the deviation of simulated results from the theoretical data.

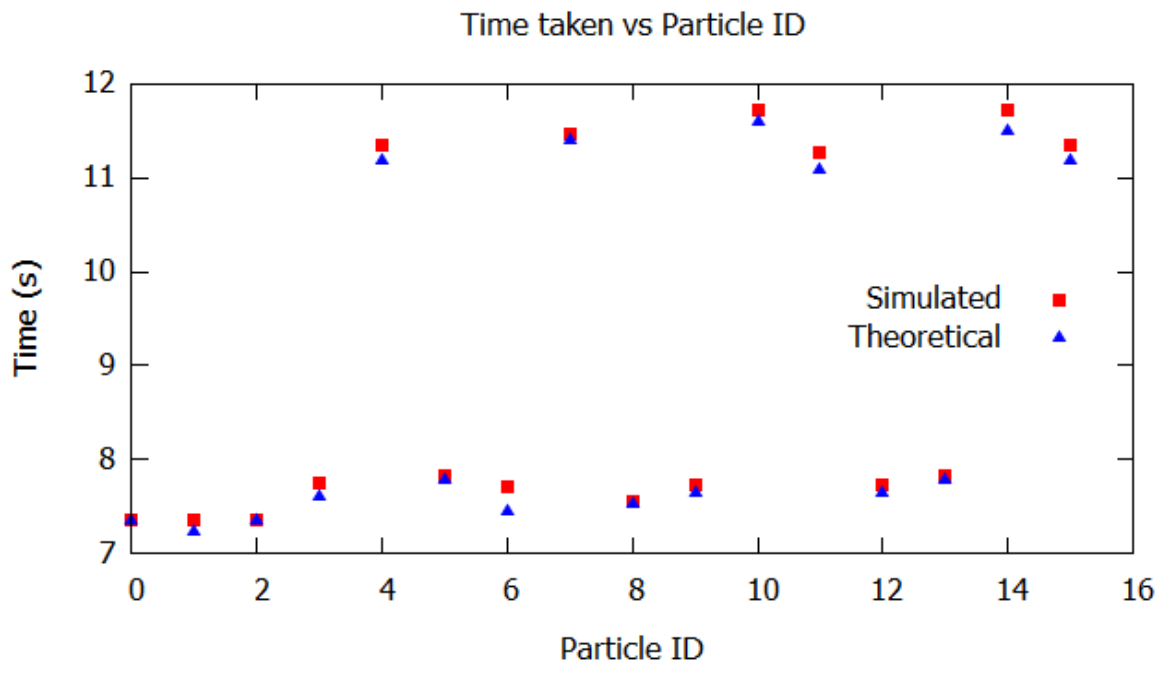

Figure 5. Time taken for particles to reach pressure node.

One can observe from Figure 5 that the error in simulated results is less than $4 \%$ when compared with the theoretical values. As the accuracy of simulation is established, simulation work is then carried out for various parametric conditions. 


\section{CHAPTER 4: RESULTS AND DISCUSSION}

This section will present the results obtained from the simulation for various parameters and will discuss the ways to optimize separation efficiency.

During the simulations, 60 particles of each type are released simultaneously at the inlet and the distribution of particles was captured at location (I), (II) and at three different outlets represented as A, B and C as illustrated in Figure 6. The separation efficiency of $3 \mu \mathrm{m}$ particles was defined as $\mathrm{B} /(\mathrm{A}+\mathrm{B}+\mathrm{C})$ and $(\mathrm{A}+\mathrm{C}) /(\mathrm{A}+\mathrm{B}+\mathrm{C})$ for the larger particles, where $\mathrm{A}, \mathrm{B}$ and $\mathrm{C}$ are the number of particles obtained at the outlets $\mathrm{A}, \mathrm{B}$ and $\mathrm{C}$ respectively.

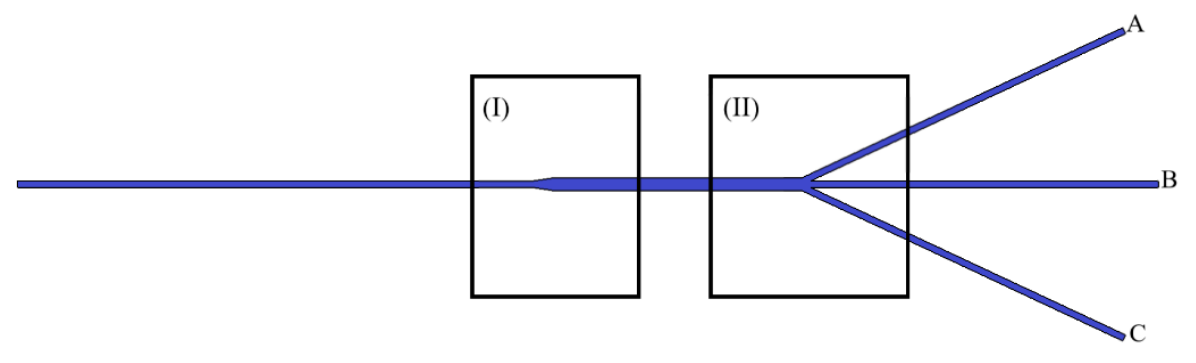

Figure 6. The chosen location (I, II) and outlets (A-C) in the microchannel for capturing the distribution of particles.

\subsection{Separation of $10 \mu \mathrm{m}$ and $3 \mu \mathrm{m}$ Particles}

During separation process, input wave length was taken as $300 \mu \mathrm{m}$ and a constant pressure amplitude (I) of $100 \mathrm{kPa}$ was applied in the first stage. An inlet mass flow rate was taken to be $8.33 \mathrm{e}-09 \mathrm{~kg} / \mathrm{s}$ as discussed in section 3 . Then the separation efficiency was calculated by varying the pressure amplitude (II) from $30 \mathrm{kPa}$ to $120 \mathrm{kPa}$ in the second stage. Figure 7 illustrates the var- 
-iation of separation efficiency results obtained as a function of pressure amplitude in the second stage.

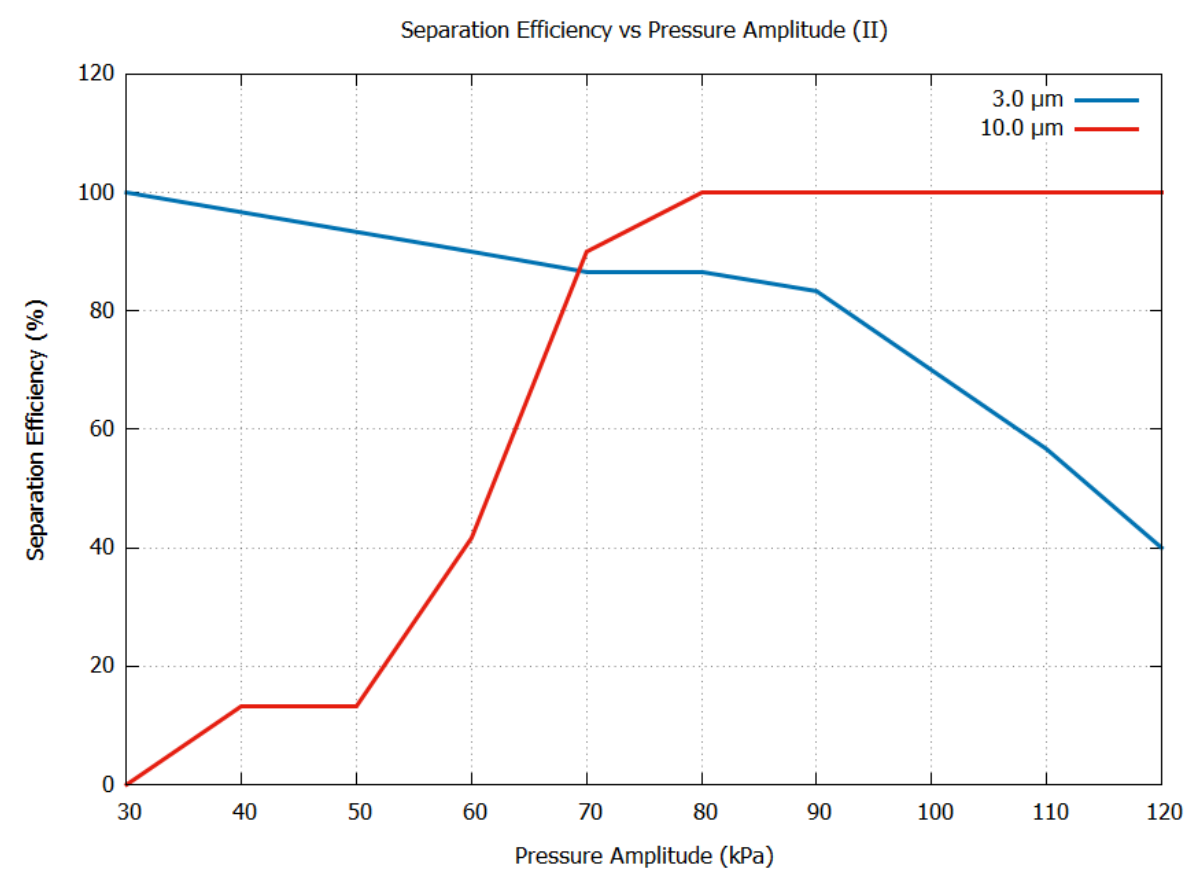

Figure 7. Variation of separation efficiency with second stage pressure amplitude.

In the second stage, acoustic radiation force (ARF) on the particles increases with the increase in pressure amplitude as it is observed from Eq. 1 that ARF is directly proportional to the square of pressure amplitude $\left(p_{o}\right)$. Due to this, as the pressure amplitude increases, number of 10 $\mu \mathrm{m}$ particles at their respective outlets increases but it also causes the $3 \mu \mathrm{m}$ particles to deviate from its path resulting in a decrease in separation efficiency. This behavior of particles is illustrated in Figure 7 when the pressure amplitude (II) is increased from $30 \mathrm{kPa}$ to $80 \mathrm{kPa}$. Also, as the pressure amplitude (II) increases to $80 \mathrm{kPa}$ the variations in the separation efficiency of $10 \mu \mathrm{m}$ particles is found to greater than that of $3 \mu \mathrm{m}$ particles. This is because, $10 \mu \mathrm{m}$ particles experiences an acoustic radiation force (ARF) 37 times than that of $3 \mu \mathrm{m}$ particles due to their relatively large volume which in turn causes larger variations in separation efficiency. 
From Figure 7, it is observed that at an optimal pressure amplitude of $80 \mathrm{kPa}$, both the particles $10 \mu \mathrm{m}$ and $3 \mu \mathrm{m}$ have a separation efficiency of $100 \%$ and $86.67 \%$ respectively. The efficiency of $3 \mu \mathrm{m}$ particles obtained can be further improved by increasing their concentration at the center of the channel. This can be attained by raising the pressure amplitude (I) in the first stage. The separation efficiency of particles obtained by varying the pressure amplitude (I) in the first stage is illustrated in Figure 8. For this set of simulations, a constant pressure amplitude (II) of $80 \mathrm{kPa}$ was applied in the second stage and the first stage pressure amplitude was varied from $30 \mathrm{kPa}$ to $130 \mathrm{kPa}$.

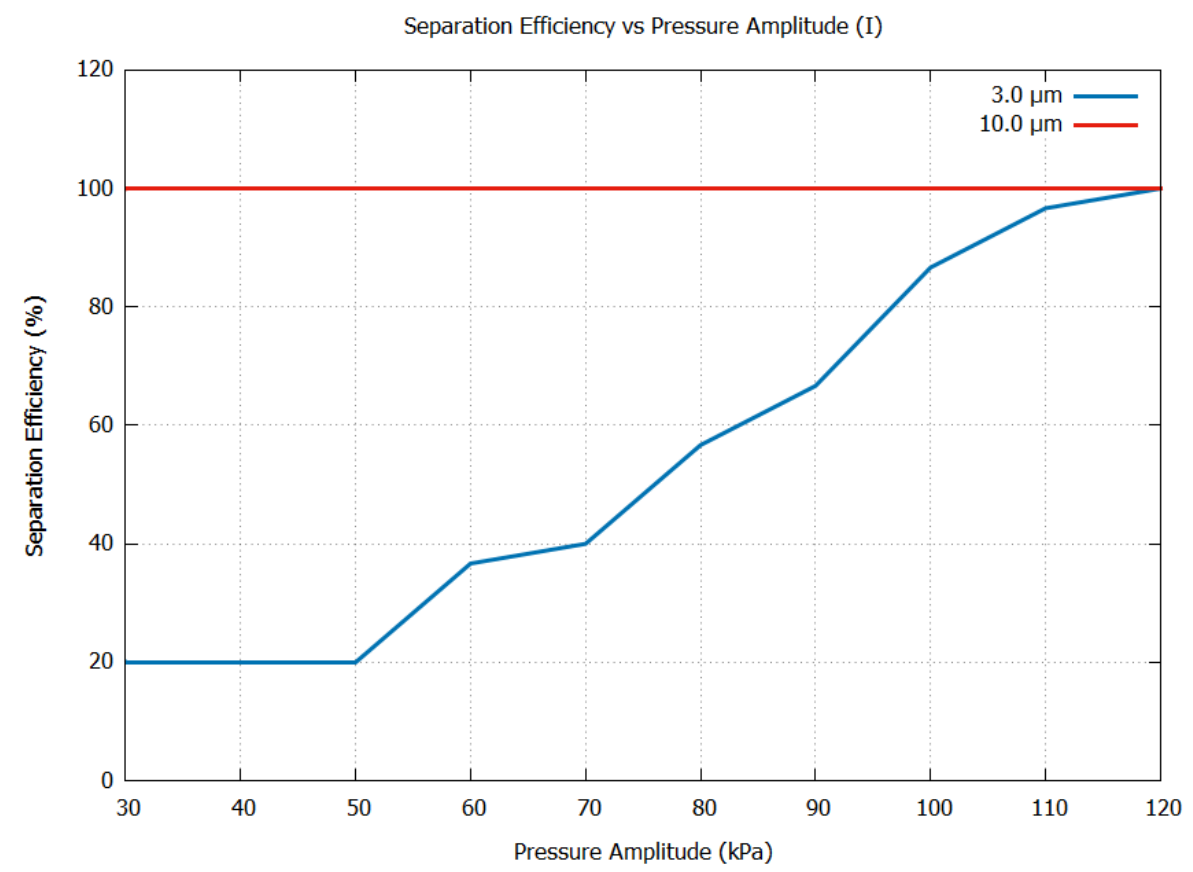

Figure 8. Variation of separation efficiency with first stage pressure amplitude.

One can observe from Figure 8 that as the pressure amplitude increases, the separation efficiency of $3 \mu \mathrm{m}$ particles increases while the efficiency remains constant at $100 \%$ for $10 \mu \mathrm{m}$ particles. This is because, even though the Pressure amplitude (I) is varied from 30 to $130 \mathrm{kPa}$, second stage pressure amplitude (II) is high enough to separate them effectively. At $110 \mathrm{kPa}$, both the particles $10 \mu \mathrm{m}$ and $3 \mu \mathrm{m}$ have a separation efficiency of $100 \%$ and $96.67 \%$ respectively. 
Hence by maintaining a pressure amplitude greater than $110 \mathrm{kPa}$ in the first stage and $80 \mathrm{kPa}$ in the second stage, a separation efficiency greater than $96 \%$ can be obtained for both the particles.

\subsection{Critical Particle Size for Acoustic Particle Separation with 3 um Particles}

A procedure similar to the one described in the section 4.1 is used for determining the critical particle size for acoustic particle separation. During the first set of simulations, input wavelength was taken as $300 \mu \mathrm{m}$ and a constant pressure amplitude (I) of $100 \mathrm{kPa}$ was applied in the first stage. An inlet mass flow rate of $8.33 \mathrm{e}-09 \mathrm{~kg} / \mathrm{s}$ was taken as inlet boundary condition. The separation efficiency was then calculated for diameter of particles varying from $5 \mu \mathrm{m}$ to $10 \mu \mathrm{m}$ at different second stage pressure amplitudes (II). Figure 9 illustrates the variation of separation efficiency with second stage pressure amplitude for particle of different sizes.

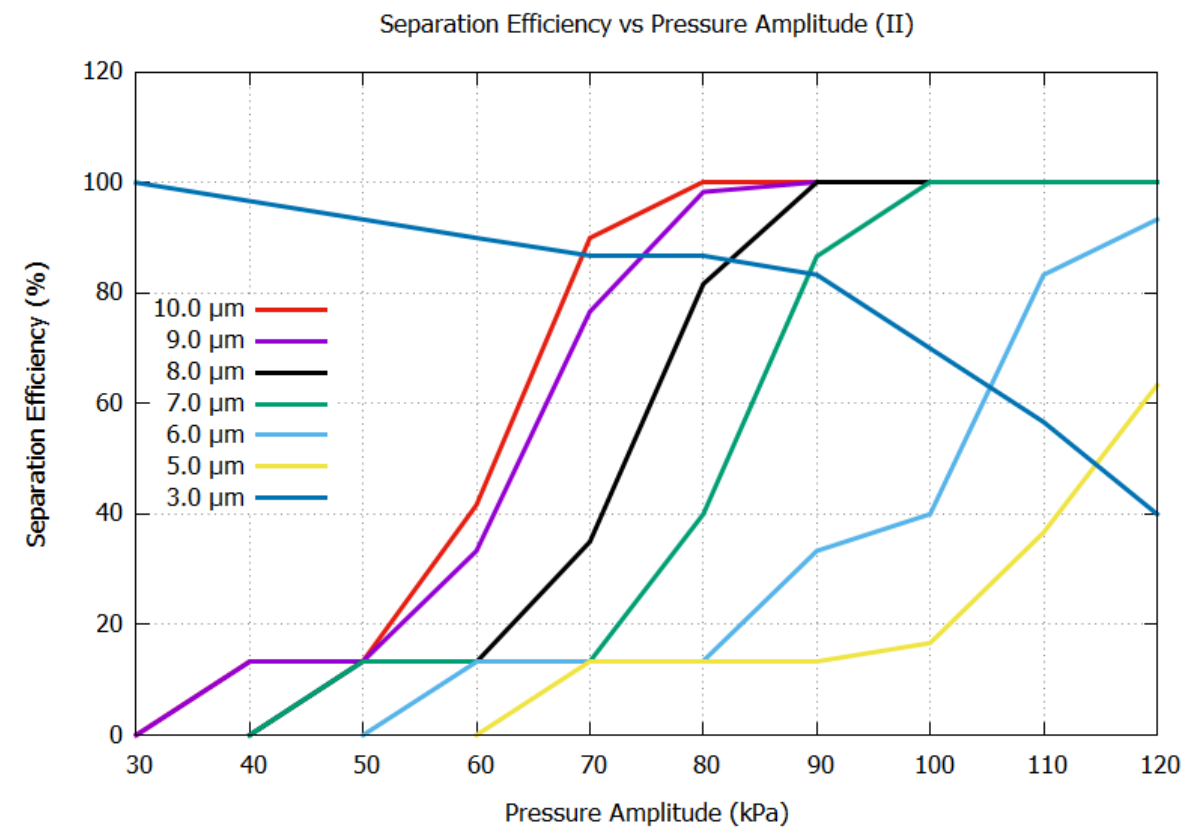

Figure 9. Variation of separation efficiency with second stage pressure amplitude.

From Figure 9, it is observed that both $3 \mu \mathrm{m}$ and $7 \mu \mathrm{m}$ particles can be separated effectively with a separation efficiency greater than $80 \%$ at $90 \mathrm{kPa}$. However, there is no optimum pressure amplitude at which $3 \mu \mathrm{m}$ and $6 \mu \mathrm{m}$ or $3 \mu \mathrm{m}$ and $5 \mu \mathrm{m}$ are separated effectively. 
The separation efficiency obtained for $3 \mu \mathrm{m}$ particles can be further improved by increasing the pressure amplitude (I) in the first stage. Figure 10 shows the variation of separation efficiency with second stage pressure amplitude (II) while the pressure amplitude (I) in the first stage was maintained at $120 \mathrm{kPa}$.

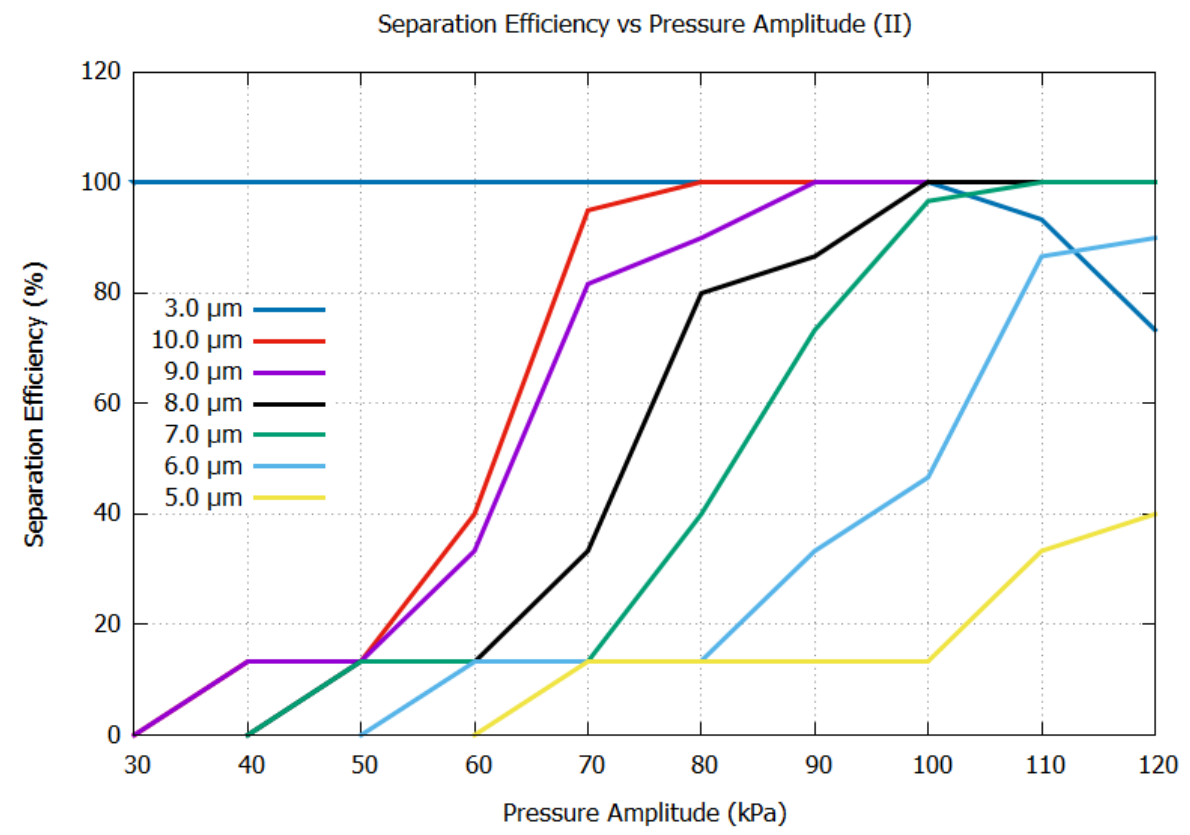

Figure 10. Variation of separation efficiency with pressure amplitude (II).

From Figure 10, it can be observed that both $3 \mu \mathrm{m}$ and $6 \mu \mathrm{m}$ particles have a separation efficiency greater than $80 \%$ at $110 \mathrm{kPa}$ pressure amplitude. However, the variation between the separation efficiency of $3 \mu \mathrm{m}$ and $5 \mu \mathrm{m}$ particles increased with the increase in first stage pressure amplitude. Hence, by maintaining a pressure amplitude greater than $120 \mathrm{kPa}$ in the first stage and $110 \mathrm{kPa}$ in the second stage the critical size of the particle that can be separated with $3 \mu \mathrm{m}$ particles is $6 \mu \mathrm{m}$.

\subsection{Effect of Flow Rate on Separation Efficiency}

During the first set of simulations, the wavelength, pressure amplitude in the first and second stage were set to $300 \mu \mathrm{m}, 120 \mathrm{kPa}$ and $110 \mathrm{kPa}$ respectively. Particles of $3 \mu \mathrm{m}$ and $6 \mu \mathrm{m}$ 
diameter were selected for the simulation as it was observed from section 4.2 that $6 \mu \mathrm{m}$ is the critical size that can be separated with $3 \mu \mathrm{m}$. The separation efficiency for the particles was then calculated for flow rates varying from $8.33 \mathrm{e}-09 \mathrm{~kg} / \mathrm{s}$ to $8.33 \mathrm{e}-08 \mathrm{~kg} / \mathrm{s}$. The variation in the separation efficiency as a function of flowrate is illustrated in Figure 11.

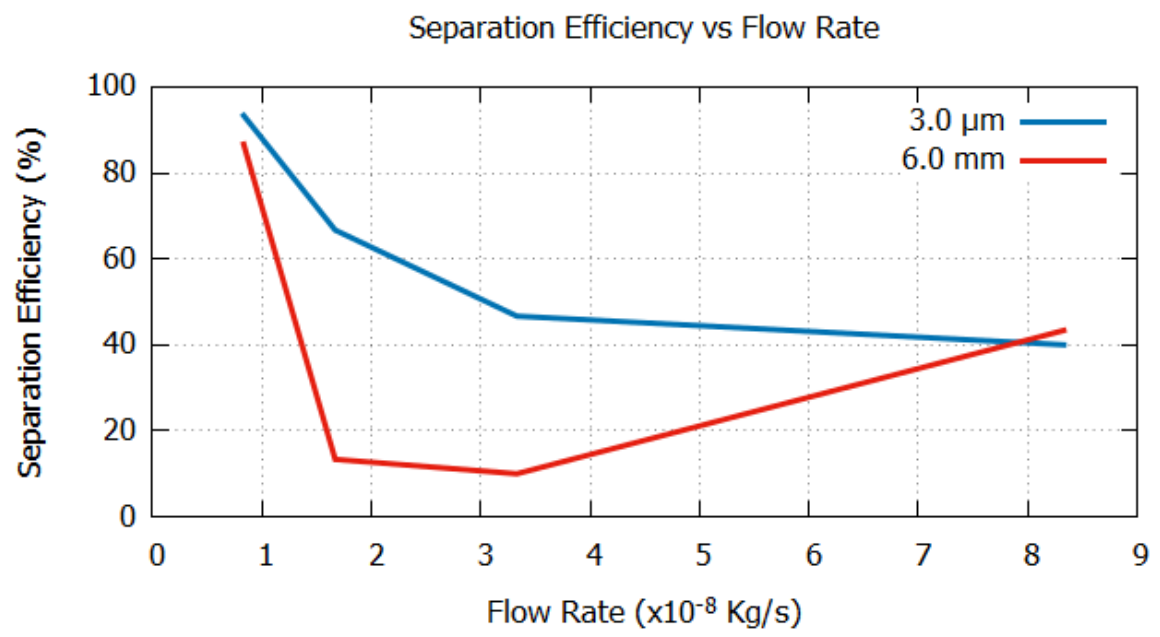

Figure 11. Separation efficiency as a function of flow rate.

From Figure 11, it is observed that as the flow rate is doubled the separation efficiency of $6 \mu \mathrm{m}$ particles decreases from $86.67 \%$ to $13.33 \%$, while it decreases from $93.33 \%$ to $66.67 \%$ for $3 \mu \mathrm{m}$ particles. The variation in separation efficiency for $6 \mu \mathrm{m}$ particles is greater than that of $3 \mu \mathrm{m}$ particles. This is because, as the flow rate is doubled, $6 \mu \mathrm{m}$ particles spend less time in the second stage thereby reducing the separation from $3 \mu \mathrm{m}$ particles. However, for $3 \mu \mathrm{m}$ particles, spending less time in second stage would decrease the deviation from their respective outlet resulting in higher separation efficiency than $6 \mu \mathrm{m}$ particles. This behavior of particles is illustrated in Figure 12 (a) and 12(b) which were captured at position (II) represented in Figure 6. 


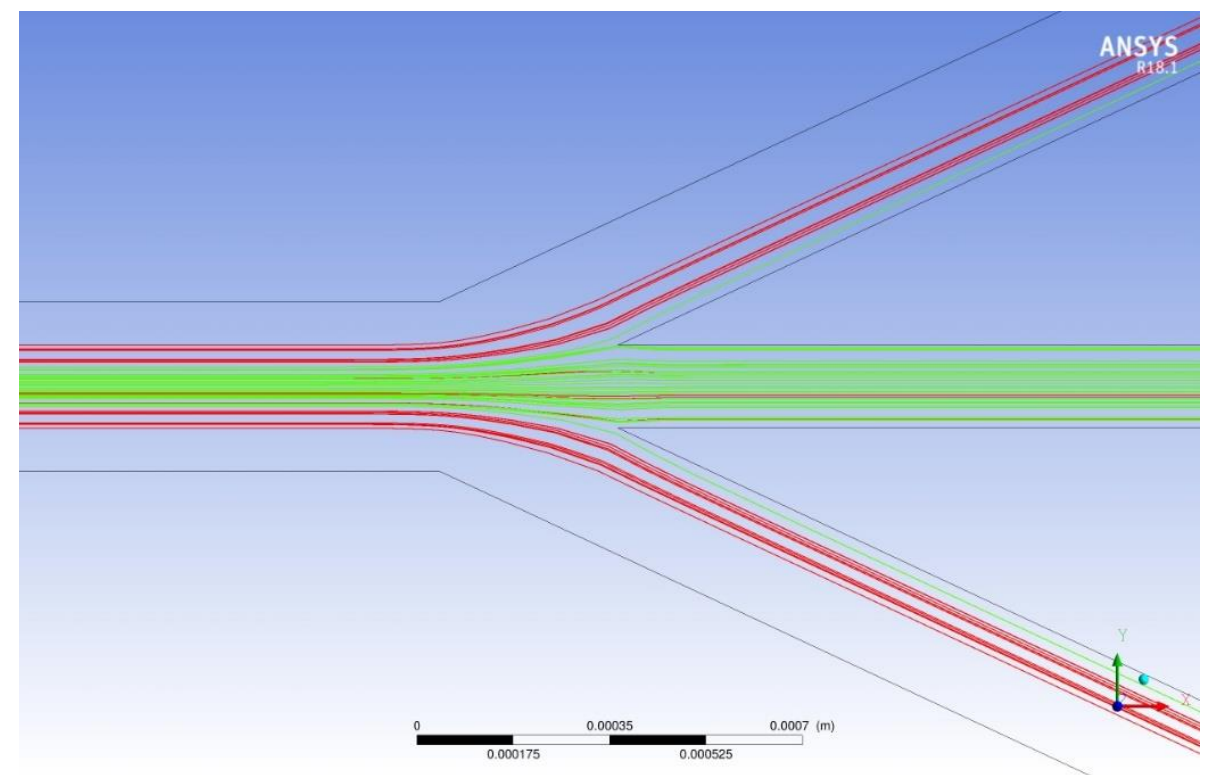

Figure 12a. Particle tracks of $3 \mu \mathrm{m}$ (green) and $6 \mu \mathrm{m}$ (red) particles at $8.33 \mathrm{e}-09 \mathrm{~kg} / \mathrm{s}$ flowrate.

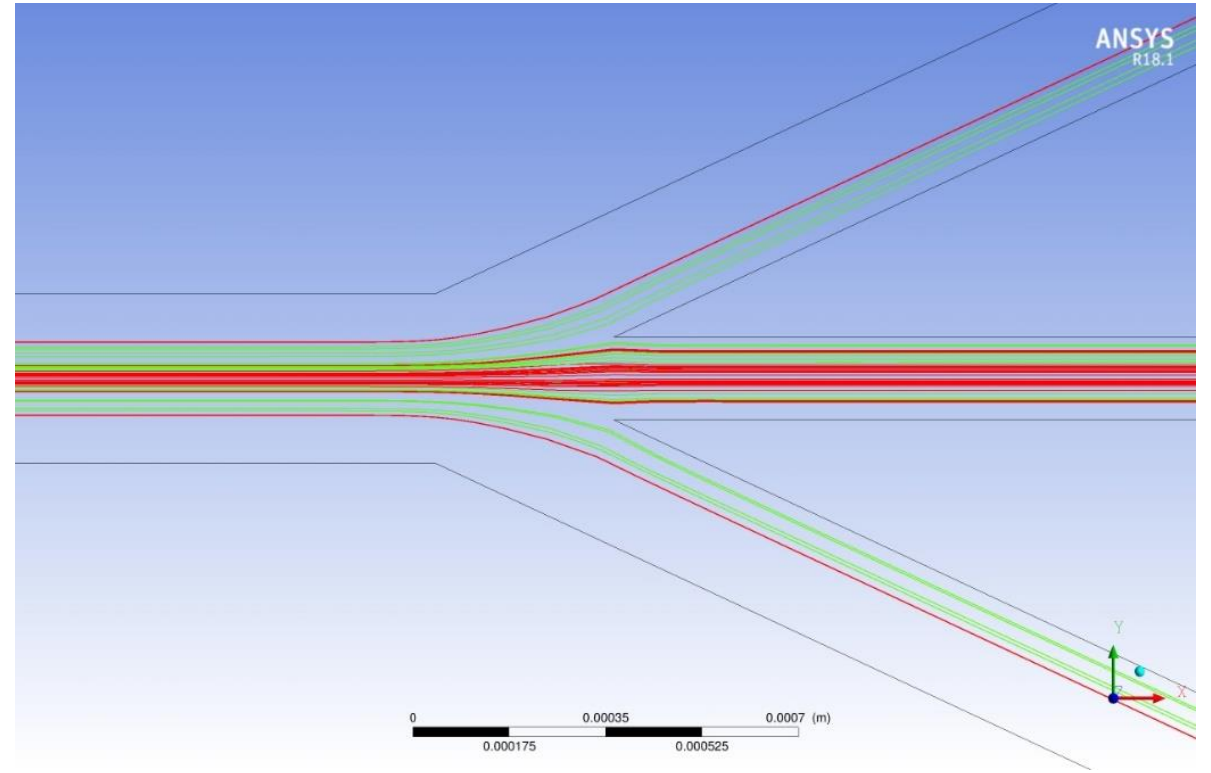

Figure 12b. Particle tracks of $3 \mu \mathrm{m}$ (green) and $6 \mu \mathrm{m}$ (red) particles at $1.67 \mathrm{e}-08 \mathrm{~kg} / \mathrm{s}$ flowrate.

As the flow rate is increased from $1.67 \mathrm{e}-08 \mathrm{~kg} / \mathrm{s}$ to $8.33 \mathrm{e}-08 \mathrm{~kg} / \mathrm{s}$ the separation efficiency for $3 \mu \mathrm{m}$ particles gradually decreases. This is expected as the concentration of $3 \mu \mathrm{m}$ particles at the center of the channel decreases with the increase in flow rate. As a result, the number of $3 \mu \mathrm{m}$ 
particles decreases at its respective outlet. This behavior in the separation efficiency of $3 \mu \mathrm{m}$ particles can be observed from Figure 13 (a) and (b).

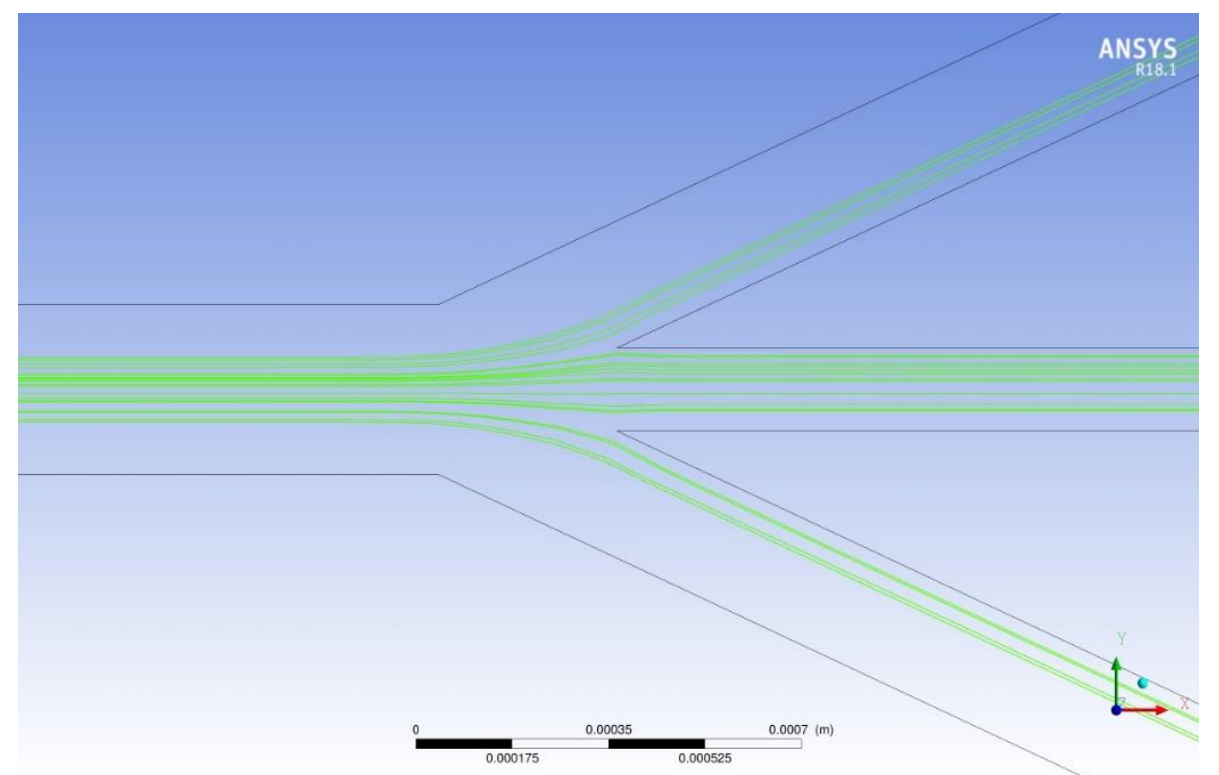

Figure 13a. Particle tracks of $3 \mu \mathrm{m}$ (green) particles at $1.67 \mathrm{e}-08 \mathrm{~kg} / \mathrm{s}$ flowrate.

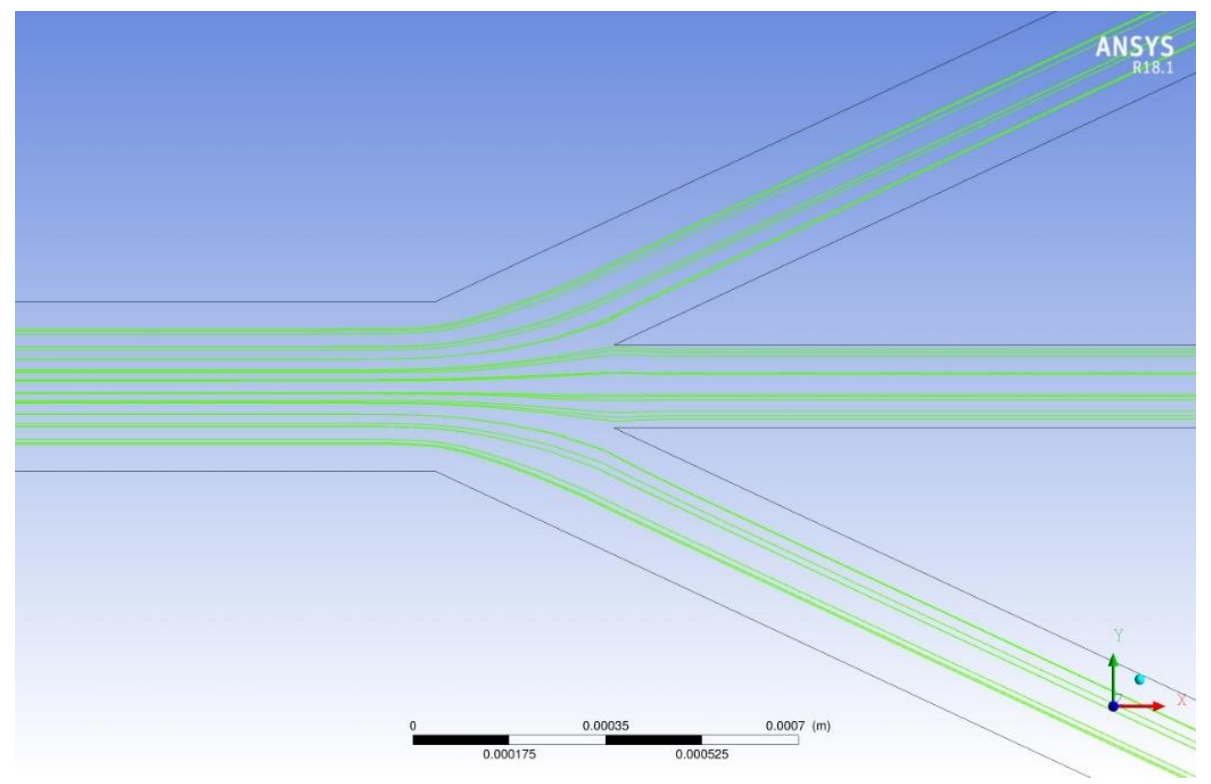

Figure 13b. Particle tracks of $3 \mu \mathrm{m}$ (green) particles at $8.33 \mathrm{e}-08 \mathrm{~kg} / \mathrm{s}$ flowrate. 


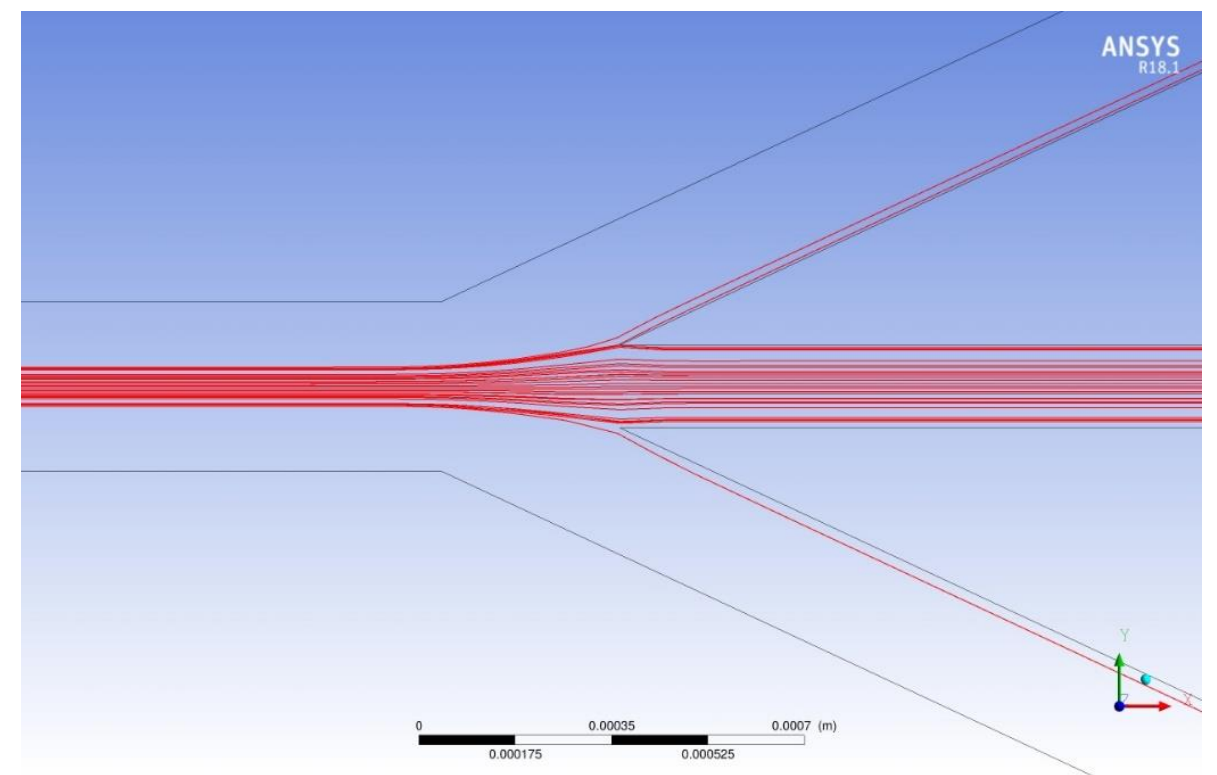

Figure 14a. Particle tracks of $6 \mu \mathrm{m}$ (red) particles at 3.33e-08 kg/s flowrate.

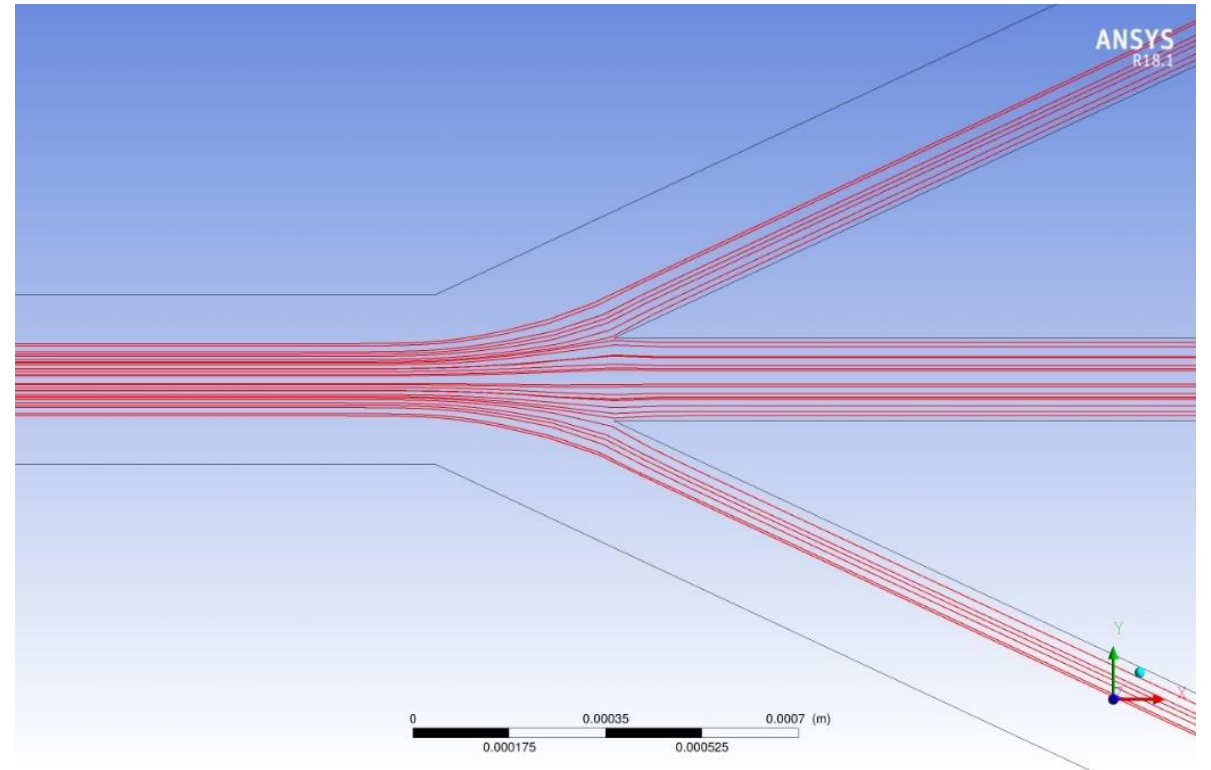

Figure 14b. Particle tracks of $6 \mu \mathrm{m}$ (red) particles at $8.33 \mathrm{e}-08 \mathrm{~kg} / \mathrm{s}$ flowrate

As illustrated in Figure 11, For $6 \mu \mathrm{m}$ particles, as the flowrate increases from $3.33 \mathrm{e}-08 \mathrm{~kg} / \mathrm{s}$ to $8.33 \mathrm{e}-08 \mathrm{~kg} / \mathrm{s}$, the concentration of particles at the center of the channel decreases. This results in an easier sorting of particles in the second stage which can be observed in Figure 14(a) and 14(b). Due to this separation efficiency of $6 \mu \mathrm{m}$ particles increases and as $6 \mu \mathrm{m}$ is the critical size 
of the particles that can be separated with $3 \mu \mathrm{m}$, the separation efficiency for particles of larger diameter will be higher than that of $6 \mu \mathrm{m}$ particles represented in Figure 11.

\subsection{Effect of Interdigital Transducer (IDT) Length on Separation Efficiency}

One of the most important parameters that decides the performance of the device is the length of IDTs. The optimum length of the IDTs required for efficient separation of particles is found by performing simulations for various IDTs lengths. During the simulation, the wavelength, the pressure amplitude in the first and second stages were set to $300 \mu \mathrm{m}, 120 \mathrm{kPa}$ and $110 \mathrm{kPa}$ respectively. Particles of $3 \mu \mathrm{m}$ and $6 \mu \mathrm{m}$ were selected for the simulation and a flowrate of $8.33 \mathrm{e}-$ $09 \mathrm{~kg} / \mathrm{s}$ was taken as the inlet condition. As the design concept is of a two-stage SSAW particle separator, the separation efficiency is found by varying the length of one stage at a time while keeping the other constant.

In the first set of simulations, the length of second stage IDTs is maintained constant at 1.7 $\mathrm{mm}$ while for the first stage it is varied from $5.7 \mathrm{~mm}$ to $9.7 \mathrm{~mm}$. The obtained separation efficiency results as a function of IDTs length is illustrated in Figure 15.

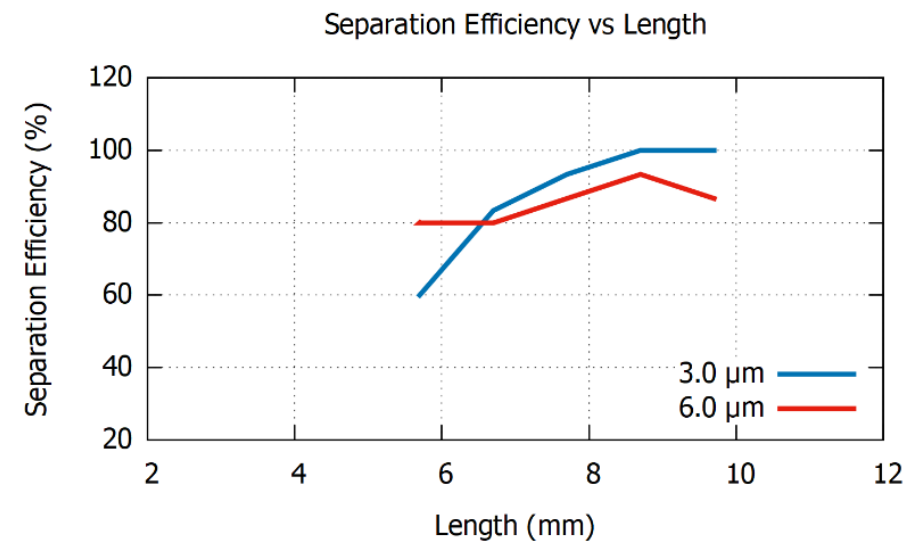

Figure 15. Separation efficiency as a function of first stage IDTs length.

From Figure 15 it is observed that the separation efficiency of $3 \mu \mathrm{m}$ particles gradually increases with the increase in IDTs length and reaches $100 \%$ at $8.7 \mathrm{~mm}$. This behavior is expected 
as the concentration of $3 \mu \mathrm{m}$ particles increases at the center of the channel with the increase in length of first stage IDTs. This results in an increased separation efficiency as the deviation of 3 $\mu \mathrm{m}$ particles from its respective outlet decreases.

As observed from the Figure 15, the separation efficiency of $6 \mu \mathrm{m}$ particles remains more or less the same with the change in first stage IDTs length. The reason for this is, IDTs of length $5.7 \mathrm{~mm}$ is sufficient enough for $6 \mu \mathrm{m}$ particles to move to the center of the channel. This behavior of particles is illustrated in the Figure 16 (a) and (b) which was captured at position I represented in Figure 6.

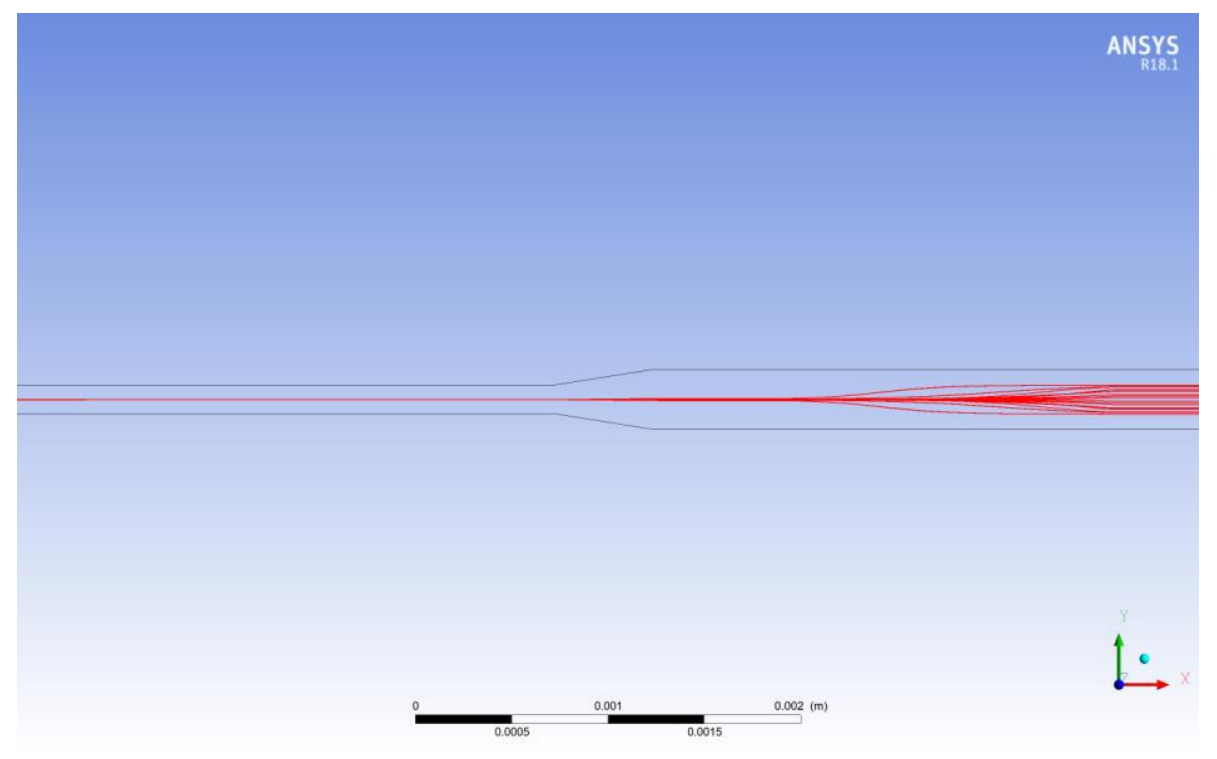

Figure 16a. Particle tracks of $6 \mu \mathrm{m}$ (red) particles at $5.7 \mathrm{~mm}$ first stage IDTs length. 


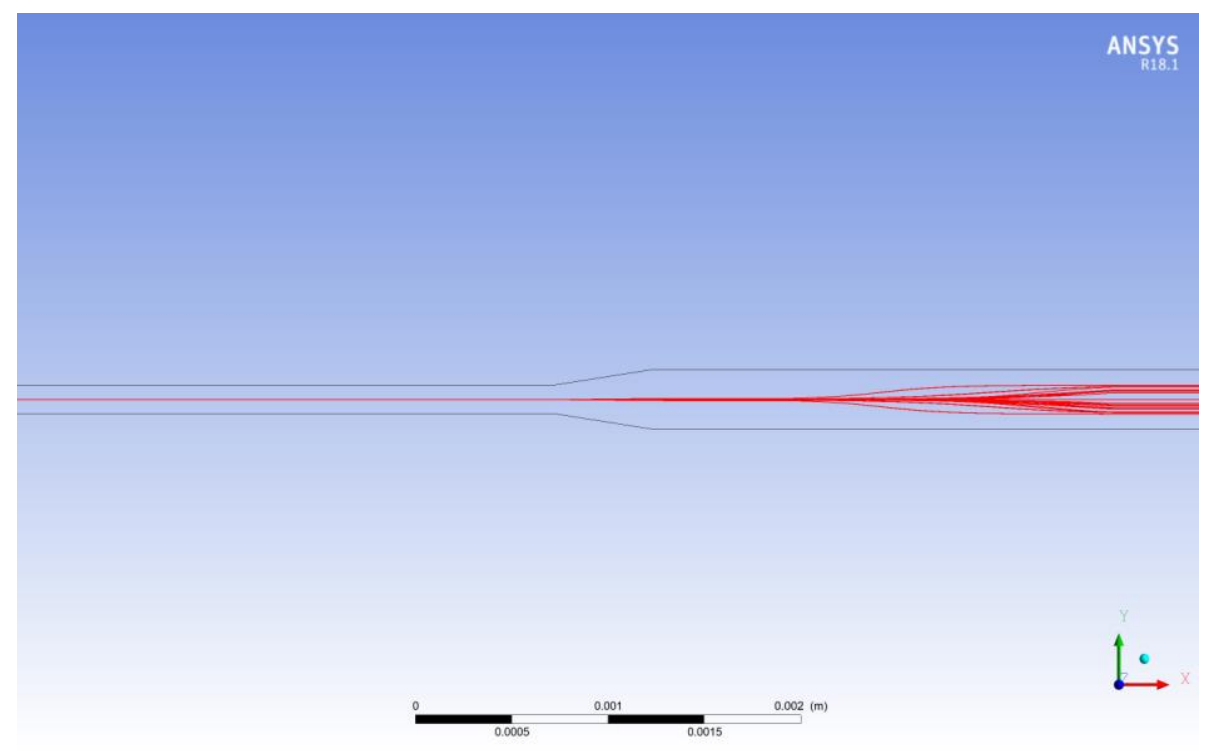

Figure 16b. Particle tracks of $6 \mu \mathrm{m}$ (red) particles $9.7 \mathrm{~mm}$ first stage IDTs length.

During the second set of simulations, IDTs length in the first stage was set to $7.7 \mathrm{~mm}$ and the length in the second stage was varied from $0.85 \mathrm{~mm}$ to $3.4 \mathrm{~mm}$. Figure 17 illustrates the obtained separation efficiency results as a function of IDTs length.

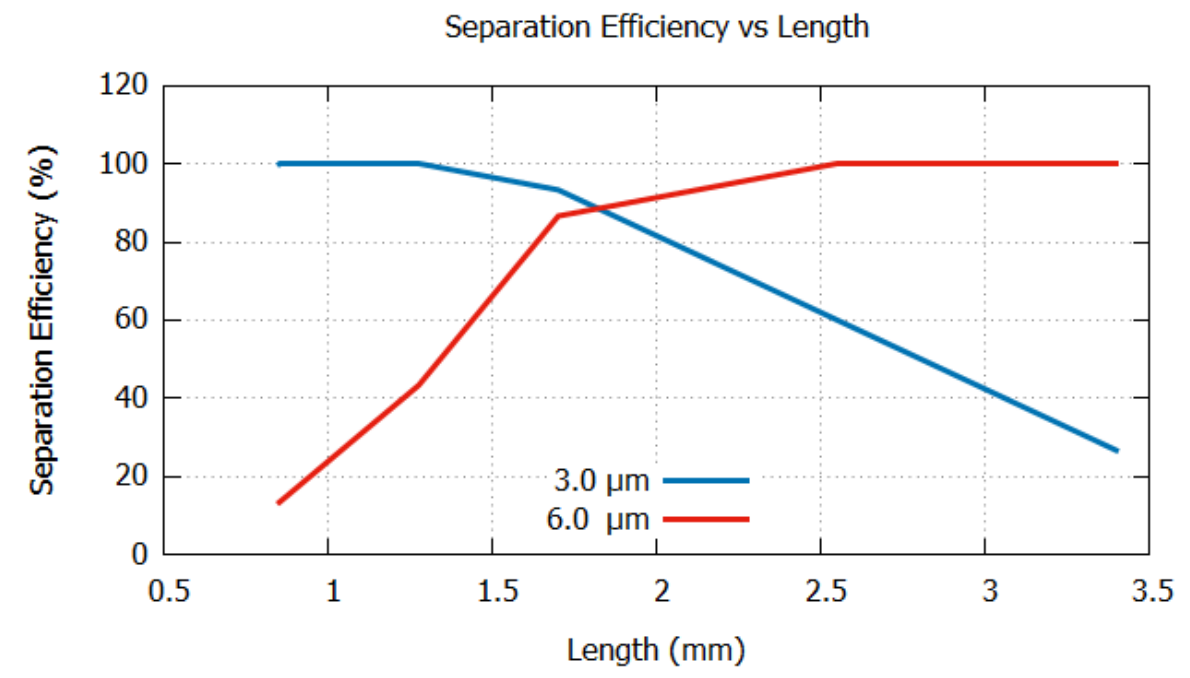

Figure 17. Separation efficiency as a function of second stage IDTs length.

From Figure 17, The optimum length of second stage IDTs was found to be $1.7 \mathrm{~mm}$ where both $3 \mu \mathrm{m}$ and $6 \mu \mathrm{m}$ particles have an efficiency of $93.33 \%$ and $86.67 \%$ respectively. For IDT's of length less than the ideal parameter, both the particles spend less time in the second stage. Due 
to this the separation of $6 \mu \mathrm{m}$ particles form $3 \mu \mathrm{m}$ decreases. For IDT's of length more than the Ideal value, both the particles experiences ARF for a relatively longer period. As a result, the deviation of $3 \mu \mathrm{m}$ particles from its respective outlet increases causing a decrease in separation efficiency. These two phenomena of the particles can be observed in Figure 17, where there was no significant separation of particles for IDTs of length less than $1.5 \mathrm{~mm}$ or greater than $2.5 \mathrm{~mm}$. Hence by maintaining second stage IDTs length of $1.7 \mathrm{~mm}$ and first stage IDTs length greater than $8.7 \mathrm{~mm}$ one could obtain high separation of particles.

\subsection{Effect of Transducer Wavelength on Separation Efficiency}

For determining the effect of transducer wavelength on separation efficiency, numerous simulations have been carried out by taking the pressure amplitudes in the first and second stage to be $120 \mathrm{kPa}$ and $110 \mathrm{kPa}$ respectively. The simulations were performed for $3 \mu \mathrm{m}$ and $6 \mu \mathrm{m}$ particles for a constant flowrate of $8.33 \mathrm{e}-09 \mathrm{~kg} / \mathrm{s}$. The separation efficiency is then calculated by varying the wavelength at one stage while keeping the other constant.

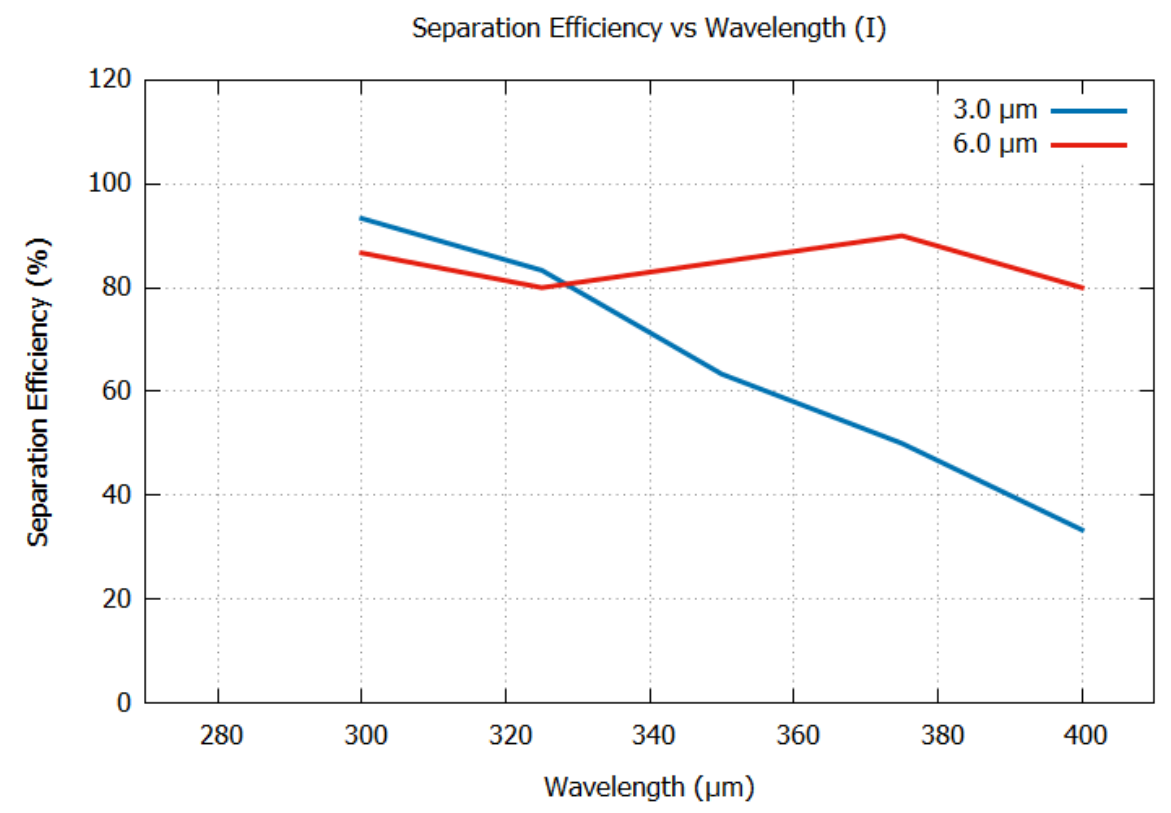

Figure 18. Separation efficiency as a function of first stage wavelength. 
In the first set of simulations, the wavelength in the first stage was varied from $300 \mu \mathrm{m}$ to $400 \mu \mathrm{m}$ while for the second stage it was maintained constant at $300 \mu \mathrm{m}$. The obtained separation efficiency as a function of wavelength (I) in the first stage is illustrated in Figure 18.

From Eq. 1, ARF on a particle is inversely proportional to the wavelength generated by the IDT's. Hence the magnitude of ARF on the particles decreases with the increase in wavelength. Due to this, the separation efficiency of $3 \mu \mathrm{m}$ particles reduces by $64.3 \%$ as the wavelength increases from $300 \mu \mathrm{m}$ to $400 \mu \mathrm{m}$ as illustrated in Figure 18. This variation in ARF experienced by $3 \mu \mathrm{m}$ particles in the first stage as a function of particle position (y) for different wavelengths is illustrated in Figure 19. For $6 \mu \mathrm{m}$ particles, as the wavelength increases, the variations observed in the separation efficiency is less than that of $3 \mu \mathrm{m}$ particles. The reason for this is, a wavelength of $300 \mu \mathrm{m}$ in the second stage is high enough to separate the particles effectively.

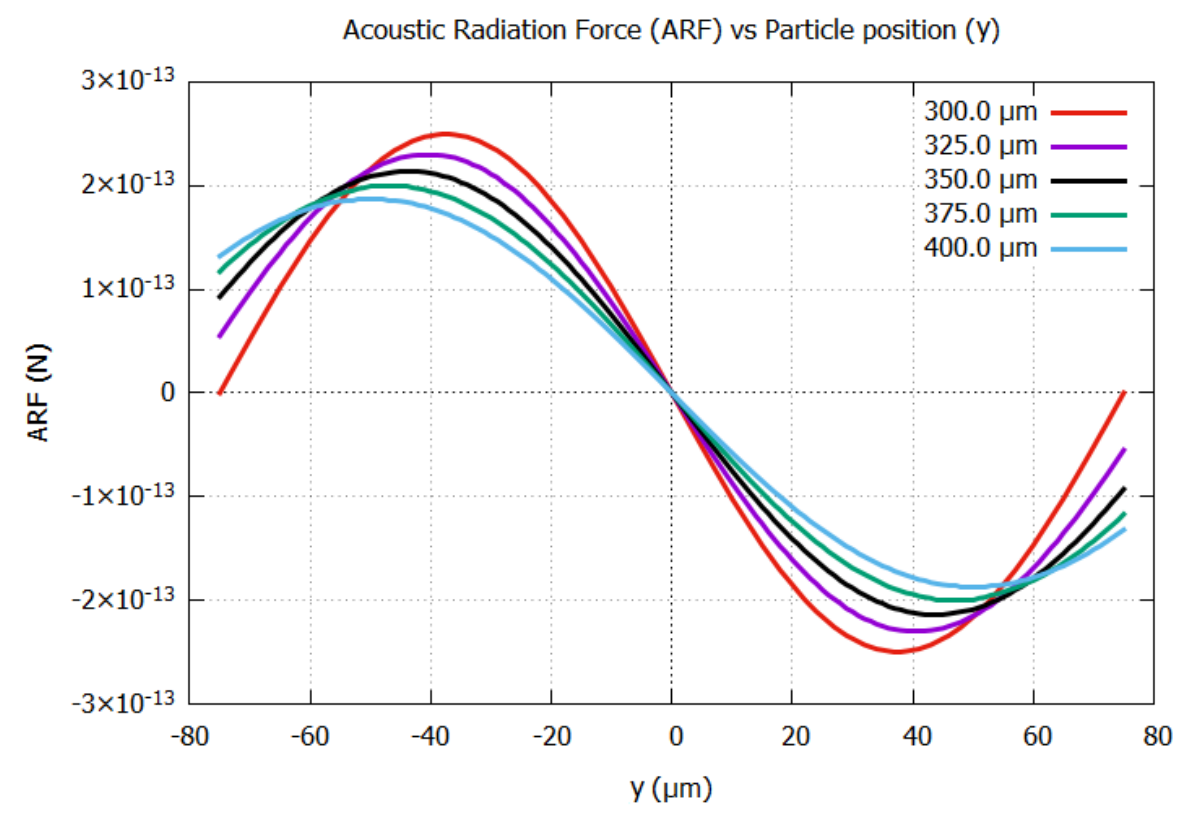

Figure 19. Variation in ARF with particle position (y) for different wavelengths.

During the second set of simulations, the wavelength in the first stage was maintained constant at $300 \mu \mathrm{m}$ while for the second stage it varied from $300 \mu \mathrm{m}$ to $400 \mu \mathrm{m}$. The obtained 
separation efficiency as a function of wavelength (II) in the second stage is illustrated in Figure 20.

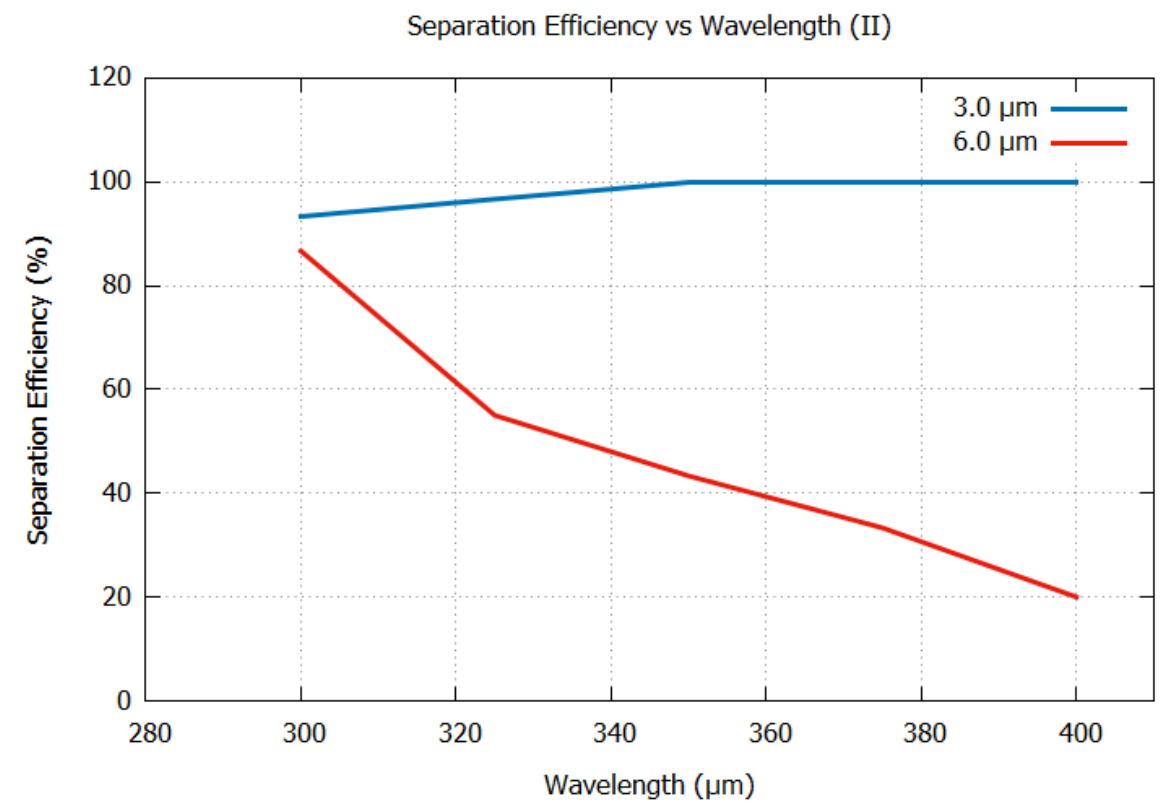

Figure 20. Separation efficiency as a function of second stage wavelength.

From Figure 20, it can be observed that the optimal wavelength in the second stage for the effective separation of particles is $300 \mu \mathrm{m}$. Hence by maintaining a wavelength of $300 \mu \mathrm{m}$ in both the stages, effective separation of particles can be achieved.

\subsection{Effect of Separator Offset on Efficiency}

Fabrication of acoustic particle separator has always been a difficult task as the geometric variations cause a significant change in the performance of the separator. One of the basic objectives during the fabrication process is to minimize the alignment errors between the microchannel and the IDT's. In this section we analyze the effect of alignment error on separation efficiency by performing simulations for various offsets. Figure 21 illustrates the offset error caused by misalignment of the microchannel. As the design of the microchannel is symmetrical about its axis, we analyze the separation efficiency by varying the offset $(\Delta y)$ in the negative 
direction of y axis only. The separation efficiency results obtained from the simulations is illustrated in Figure 22 as a function of offset $(\Delta y)$.

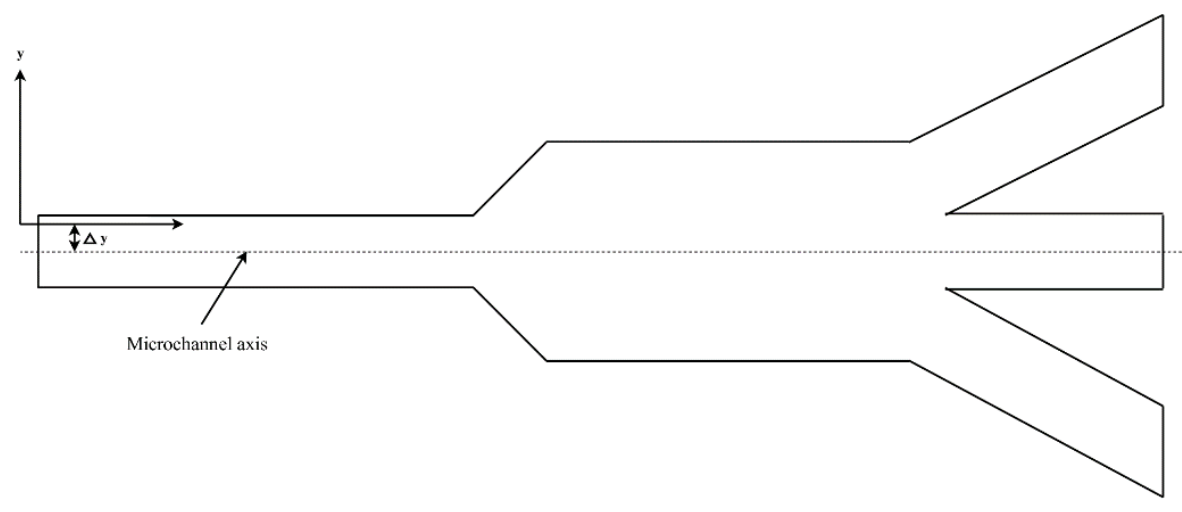

Figure 21. Offset $(\Delta y)$ due to misalignment between microchannel and IDT's.

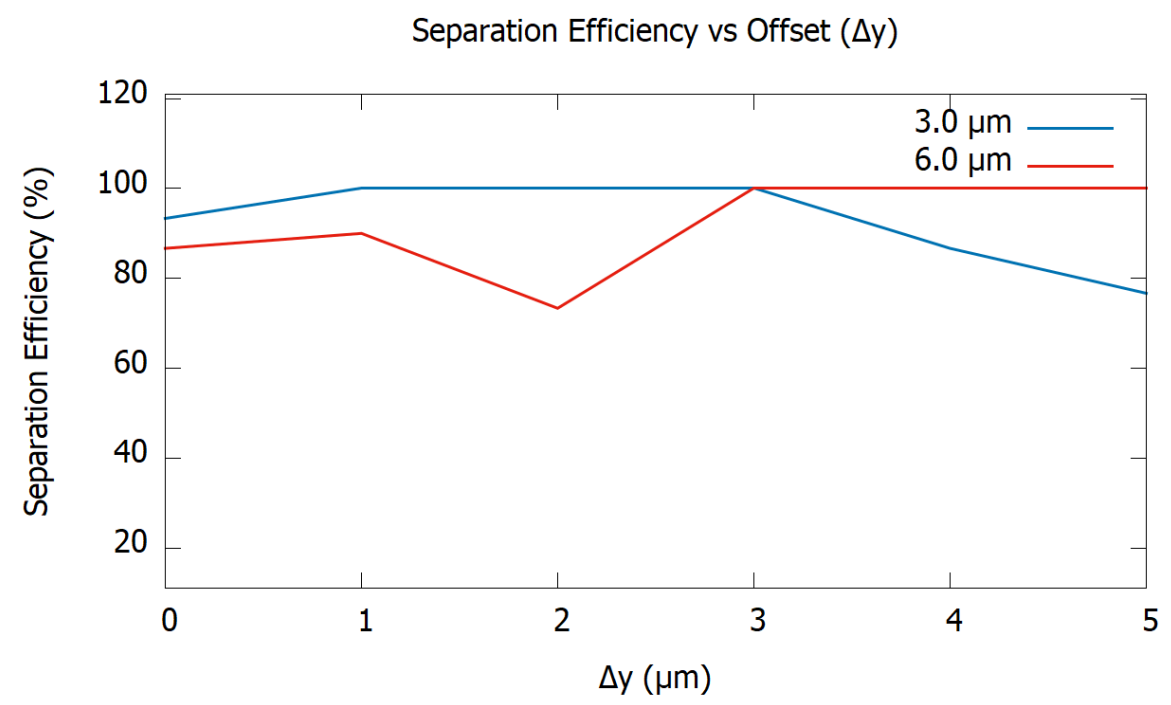

Figure 22. Separation efficiency as a function of offset $(\Delta y)$.

As illustrated in Figure 22, for $6 \mu \mathrm{m}$ particles, as the offset $(\Delta \mathrm{y})$ increases from $1 \mu \mathrm{m}$ to 3 $\mu \mathrm{m}$, the separation efficiency of particles decreases and increases. This is because of transition of $6 \mu \mathrm{m}$ particles to the closest pressure node. This behavior of particles can be observed in Figure 23 (a) and 23 (b). 


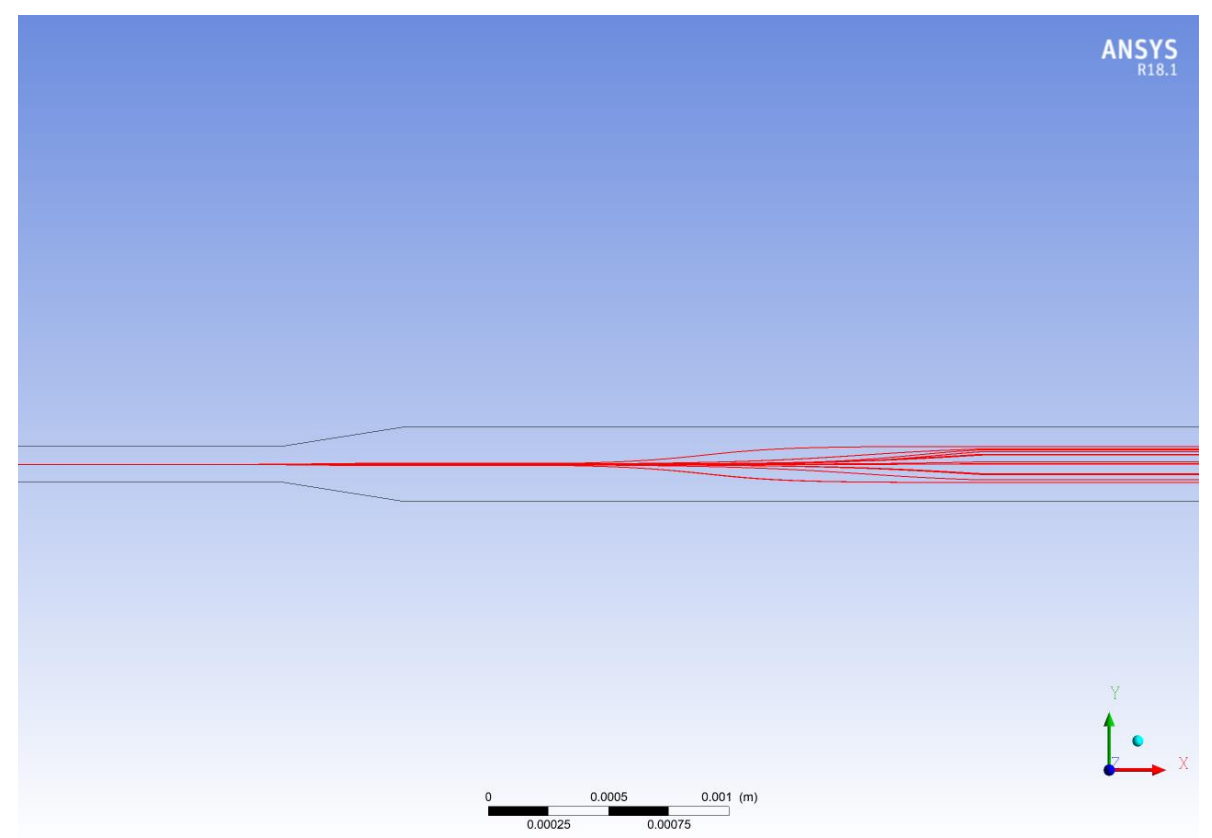

Figure 23a. Tracks of $6 \mu \mathrm{m}$ particles (red) at $1 \mu \mathrm{m}$ offset.

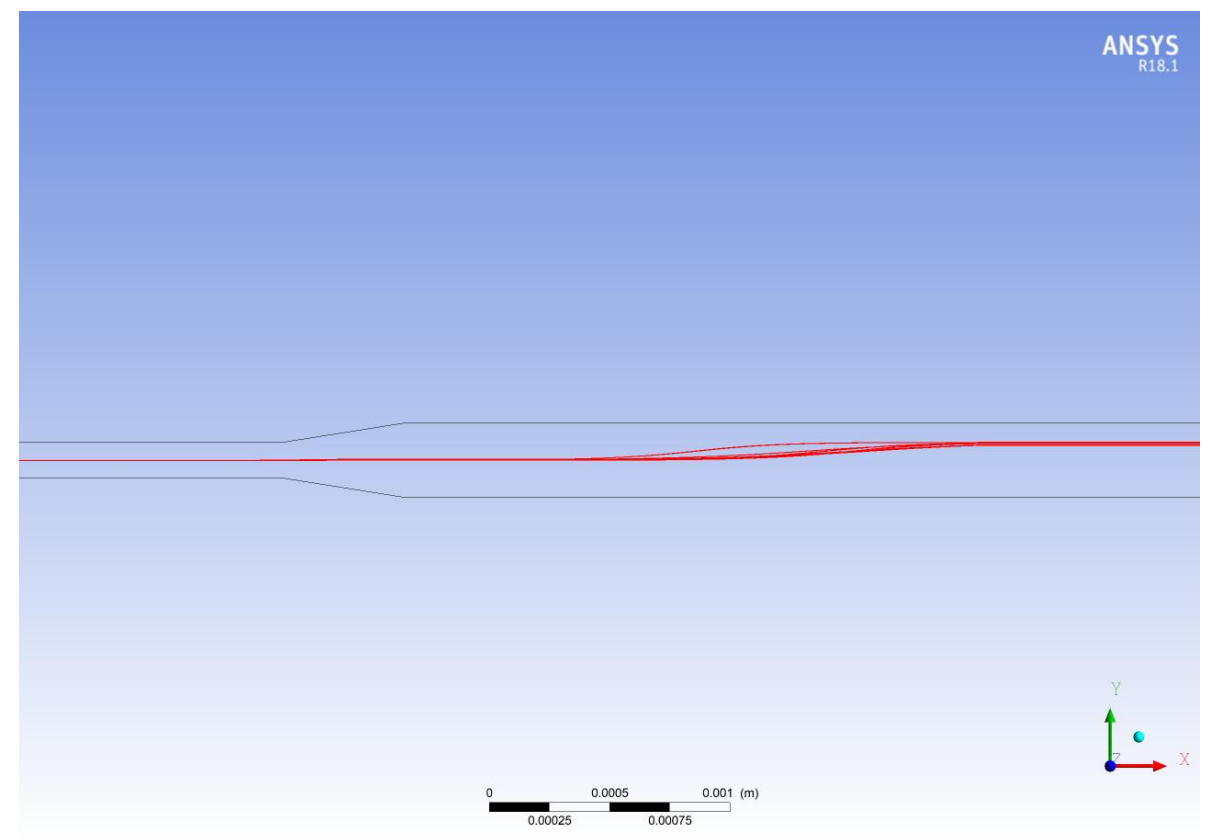

Figure 23b. Tracks of $6 \mu \mathrm{m}$ particles $(\mu \mathrm{m})$ at $3 \mu \mathrm{m}$ offset.

The separation efficiency of $3 \mu \mathrm{m}$ particles decreases beyond the offset of $3 \mu \mathrm{m}$ as illustrated in Figure 22. From the simulation results and by considering the performance of the 
separator, it should be taken care that the offset error will not exceed $5 \mu \mathrm{m}$ during fabrication process. 


\section{CHAPTER 5: CONCLUSION AND FUTURE WORK}

This section presents the conclusions drawn from the simulation work and will also gives an idea on how to calibrate acoustic particle separator. The findings in the present work will help in designing SSAW driven microfluidic devices and in increasing the efficiency of particle separation.

\subsection{Summary}

A simulation model which demonstrates the particle separation by acoustic radiation force have been developed using ANSYS® Fluent. Through theoretical and simulation data, the accuracy of the simulations has been analyzed and it is found to have an error less than $4 \%$. As the pressure amplitude in the first and second stage is increased to $80 \mathrm{kPa}$ and $110 \mathrm{kPa}$ respectively, the optimization study performed have found to enhance the separation efficiency over $96 \%$ for both 10 and $3 \mu \mathrm{m}$ particles. Also, the critical size polystyrene of particles that can be separated with $3 \mu \mathrm{m}$ was found to be $6 \mu \mathrm{m}$. The parameters for which optimum separation efficiency can be obtained for $3 \mu \mathrm{m}$ and $6 \mu \mathrm{m}$ particles is listed in Table 2 .

Table 2. Ideal parameter values for $3 \mu \mathrm{m}$ and $6 \mu \mathrm{m}$ particles separation.

\begin{tabular}{|c|c|c|}
\hline S.No. & Parameter & Ideal value \\
\hline 1 & First stage pressure amplitude & $120 \mathrm{kPa}$ \\
\hline 2 & Second stage pressure amplitude & $110 \mathrm{kPa}$ \\
\hline 3 & Flow rate & $<8.33 \mathrm{e}-09 \mathrm{~kg} / \mathrm{s}$ \\
\hline
\end{tabular}


Table 2. (Continued)

\begin{tabular}{|c|c|c|}
\hline 4 & First stage IDT's length & $>8.7 \mathrm{~mm}$ \\
\hline 5 & Second stage IDT's length & $1.7 \mathrm{~mm}$ \\
\hline 6 & Wavelength & $300 \mu \mathrm{m}$ \\
\hline 7 & Offset & $<5 \mu \mathrm{m}$ \\
\hline
\end{tabular}

As $6 \mu \mathrm{m}$ is the critical size of the particles that can be separated with $3 \mu \mathrm{m}$, the separation efficiency for particles of larger diameter will be higher than that of $6 \mu \mathrm{m}$ particles that is obtained by utilizing the parameters listed in Table 2 .

\subsection{Future Work}

The simulation model developed in this study considers the application of acoustic radiation force on the particles without other factors like particle collisions and the effect of temperature. Improvements to the current model can be made by considering these factors into account which would eliminate any further errors present. While every effort was made to design a simulation model with high levels of accuracy, the results obtained can be further refined by verifying it experimentally.

In the simulation study performed, future work will include multichannel (three+) cell sorting and also seek to extend separation process for particles other than polystyrene fluorescent particles. This work could be performed by changing the properties of the particle in ANSYS® FLUENT. Implementing the results derived from such work in designing the particle separator will allow the designer to accurately predict and improve the performance of the device. 


\section{REFERENCES}

1. Plouffe, B.D., S.K. Murthy, and L.H. Lewis, Fundamentals and Application of Magnetic Particles in Cell Isolation and Enrichment. Reports on progress in physics. Physical Society (Great Britain), 2015. 78(1): p. 016601-016601.

2. Guldiken, R., et al., Sheathless size-based acoustic particle separation. Sensors (Basel), 2012. 12(1): p. 905-22.

3. Jo, M.C. and R. Guldiken, Active density-based separation using standing surface acoustic waves. Sensors and Actuators A: Physical, 2012. 187: p. 22-28.

4. Jo, M.C. and R. Guldiken, Dual surface acoustic wave-based active mixing in a microfluidic channel. Sensors and Actuators A: Physical, 2013. 196: p. 1-7.

5. Li, P., et al., Acoustic separation of circulating tumor cells. Proceedings of the National Academy of Sciences of the United States of America, 2015. 112(16): p. 4970-4975.

6. Guo, F., et al., Three-dimensional manipulation of single cells using surface acoustic waves. Proceedings of the National Academy of Sciences, 2016. 113(6): p. 1522.

7. Ding, X., et al., Surface acoustic wave microfluidics. Lab on a Chip, 2013. 13(18): p. 36263649.

8. Imani, R.J. and E. Robert, Acoustic separation of submicron solid particles in air. Ultrasonics, 2015. 63: p. 135-140.

9. Ding, X., et al., Standing surface acoustic wave (SSAW) based multichannel cell sorting. Lab on a chip, 2012. 12(21): p. 4228-4231.

10. $\mathrm{Hu}, \mathrm{J} .$, Ultrasonic Micro/Nano Manipulations. 2013: WORLD SCIENTIFIC.

11. Liu, S., et al., Investigation into the Effect of Acoustic Radiation Force and Acoustic Streaming on Particle Patterning in Acoustic Standing Wave Fields. Sensors (Basel, Switzerland), 2017. 17(7): p. 1664.

12. Shi, J., et al., Continuous particle separation in a microfluidic channel via standing surface acoustic waves (SSAW). Lab Chip, 2009. 9(23): p. 3354-9.

13. King, L.V., On the acoustic radiation pressure on spheres. Proceedings of the Royal Society of London. Series A - Mathematical and Physical Sciences, 1934. 147(861): p. 212. 
14. Yosioka, K. and Y. Kawasima, Acoustic radiation pressure on a compressible sphere. Acta Acustica united with Acustica, 1955. 5(3): p. 167-173.

15. Laurell, T., F. Petersson, and A. Nilsson, Chip integrated strategies for acoustic separation and manipulation of cells and particles. Chemical Society Reviews, 2007. 36(3): p. 492506.

16. Xiong, G., et al., Simulation of blood flow in deformable vessels using subject-specific geometry and spatially varying wall properties. International journal for numerical methods in biomedical engineering, 2011. 27(7): p. 1000-1016.

17. Chen, Y., et al., Simulation of avascular tumor growth by agent-based game model involving phenotype-phenotype interactions. Scientific Reports, 2015. 5: p. 17992.

18. ANSYS® Academic Research. Release 18.1 ed. Vol. Fluent User's Guide. 2017: ANSYS Inc. 


\section{APPENDIX A: USER DEFINED FUNCTION}

\section{A.1 Acoustic Radiation Force}

This appendix discusses the development of user defined function (UDF) for the application of acoustic radiation force experienced by the particles in fluid flow. A sample UDF code developed for the separation particles is illustrated below.

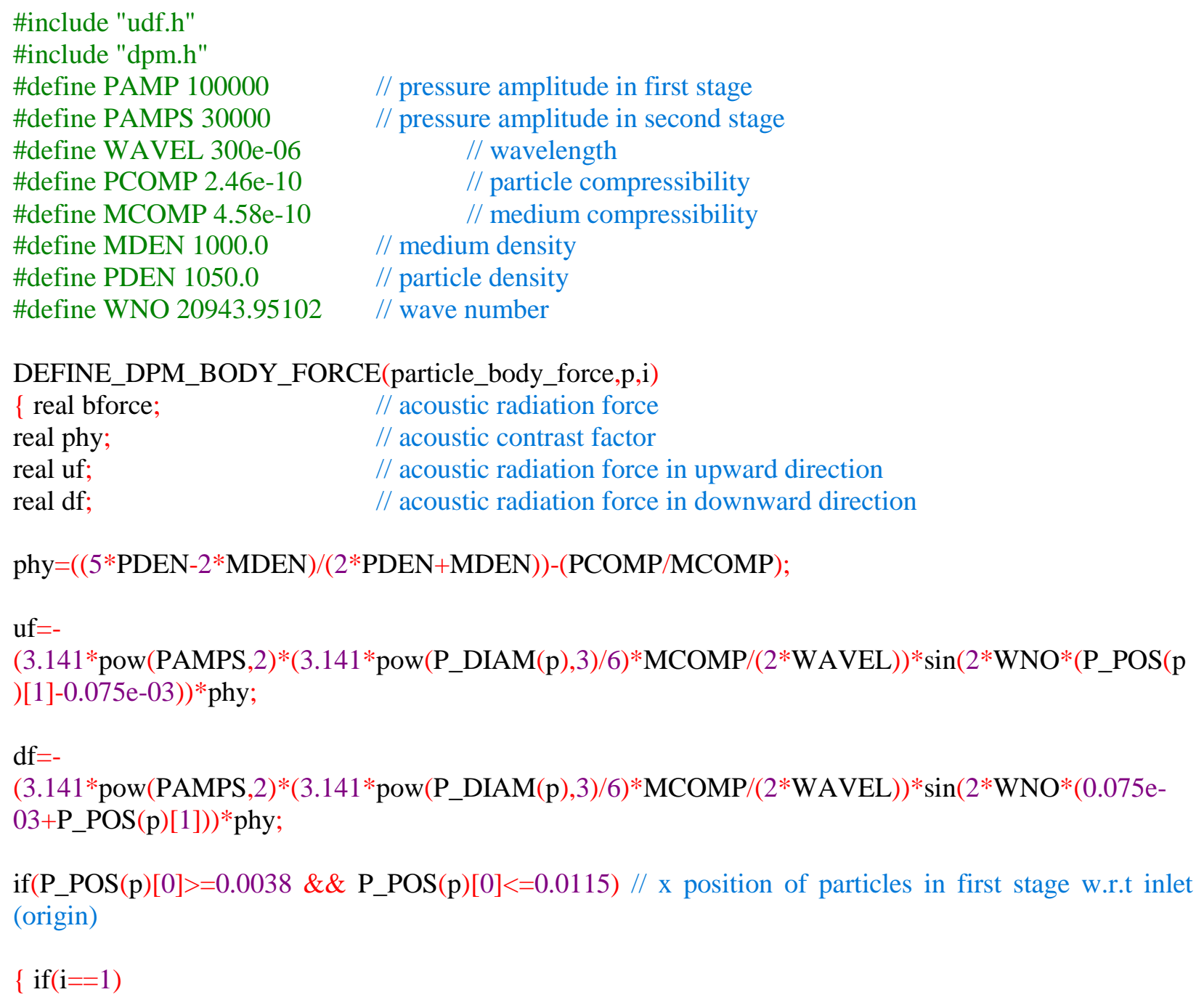




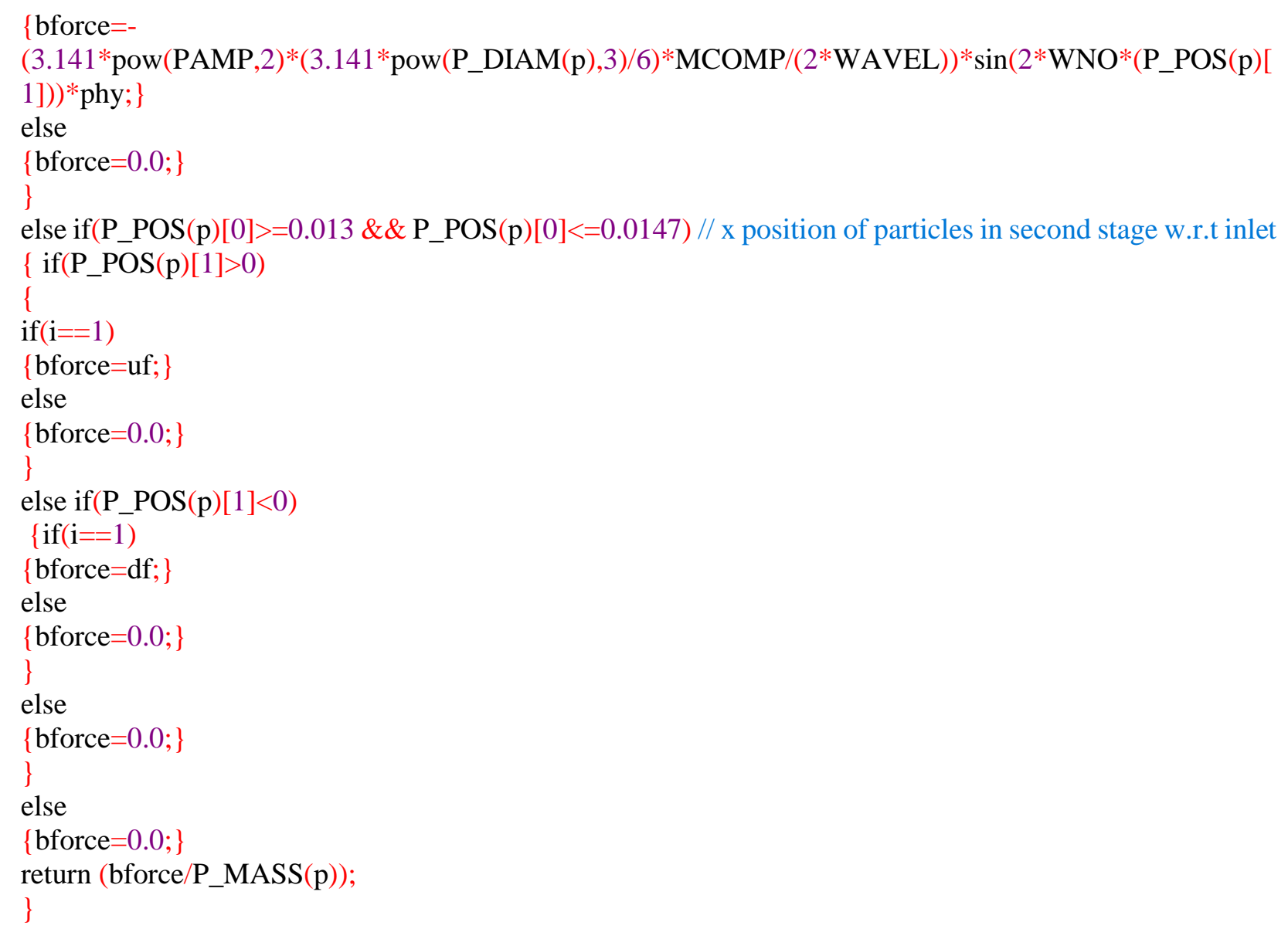




\section{APPENDIX B: SEPARATION EFFICIENCY}

This section discusses a simple $\mathrm{C}++$ code which is used to calculate the number of particles obtained at each outlet by utilizing the data obtained from the track history file. A sample part of a track history file is illustrated below.

\begin{tabular}{|c|c|c|c|c|}
\hline \multirow{2}{*}{\multicolumn{5}{|c|}{ FILE TYPE: 1}} \\
\hline & & & & \\
\hline \multicolumn{5}{|c|}{ TITLE: TRACK HISTORY } \\
\hline \multicolumn{5}{|c|}{ COLUMN TYPE VARIABLE (UNITS) } \\
\hline \multicolumn{5}{|c|}{ 12 ParticlePecidenceTime (s) } \\
\hline \multicolumn{5}{|c|}{12 ParticleResidenceTime (s) } \\
\hline \multicolumn{5}{|c|}{210 ParticleID - } \\
\hline \multicolumn{5}{|c|}{3 10 ParticleYPosition (m) } \\
\hline \multicolumn{5}{|c|}{410 ParticleXPosition (m) } \\
\hline \multicolumn{5}{|c|}{510 ParticleTimeStep (s) } \\
\hline $0.00 \mathrm{E}+00$ & $0.00 \mathrm{E}+00$ & $5.25 \mathrm{E}-05$ & $1.97 \mathrm{E}-10$ & $0.00 \mathrm{E}+00$ \\
\hline 1.93E-04 & $0.00 \mathrm{E}+00$ & $5.25 \mathrm{E}-05$ & $4.55 \mathrm{E}-08$ & $1.93 \mathrm{E}-04$ \\
\hline $9.16 \mathrm{E}-03$ & $0.00 \mathrm{E}+00$ & $5.18 \mathrm{E}-05$ & 4.29E-06 & 8.97E-03 \\
\hline $1.80 \mathrm{E}-02$ & $0.00 \mathrm{E}+00$ & $5.10 \mathrm{E}-05$ & 8.58E-06 & 8.87E-03 \\
\hline $2.66 \mathrm{E}-02$ & $0.00 \mathrm{E}+00$ & $5.01 \mathrm{E}-05$ & $1.29 \mathrm{E}-05$ & 8.57E-03 \\
\hline 3.49E-02 & $0.00 \mathrm{E}+00$ & $4.92 \mathrm{E}-05$ & $1.71 \mathrm{E}-05$ & 8.27E-03 \\
\hline 4.29E-02 & $0.00 \mathrm{E}+00$ & $4.82 \mathrm{E}-05$ & $2.14 \mathrm{E}-05$ & 7.98E-03 \\
\hline $5.06 \mathrm{E}-02$ & $0.00 \mathrm{E}+00$ & 4.72E-05 & $2.56 \mathrm{E}-05$ & 7.70E-03 \\
\hline $5.80 \mathrm{E}-02$ & $0.00 \mathrm{E}+00$ & 4.60E-05 & $2.98 \mathrm{E}-05$ & 7.43E-03 \\
\hline $6.43 \mathrm{E}-02$ & $0.00 \mathrm{E}+00$ & $4.50 \mathrm{E}-05$ & $3.35 \mathrm{E}-05$ & $6.25 \mathrm{E}-03$ \\
\hline 7.12E-02 & $0.00 \mathrm{E}+00$ & 4.38E-05 & 3.79E-05 & $6.92 \mathrm{E}-03$ \\
\hline 7.33E-02 & $0.00 \mathrm{E}+00$ & 4.34E-05 & 3.94E-05 & 2.17E-03 \\
\hline 7.93E-02 & $0.00 \mathrm{E}+00$ & $4.26 \mathrm{E}-05$ & 4.38E-05 & $6.00 \mathrm{E}-03$ \\
\hline 8.47E-02 & $0.00 \mathrm{E}+00$ & 4.21E-05 & $4.81 \mathrm{E}-05$ & $5.35 \mathrm{E}-03$ \\
\hline 8.99E-02 & $0.00 \mathrm{E}+00$ & 4.17E-05 & $5.24 \mathrm{E}-05$ & $5.21 \mathrm{E}-03$ \\
\hline $9.50 \mathrm{E}-02$ & $0.00 \mathrm{E}+00$ & 4.14E-05 & $5.68 \mathrm{E}-05$ & $5.10 \mathrm{E}-03$ \\
\hline $1.00 \mathrm{E}-01$ & $0.00 \mathrm{E}+00$ & 4.11E-05 & $6.11 \mathrm{E}-05$ & $5.00 \mathrm{E}-03$ \\
\hline $1.05 \mathrm{E}-01$ & $0.00 \mathrm{E}+00$ & $4.08 \mathrm{E}-05$ & $6.54 \mathrm{E}-05$ & $4.90 \mathrm{E}-03$ \\
\hline $1.10 \mathrm{E}-01$ & $0.00 \mathrm{E}+00$ & $4.06 \mathrm{E}-05$ & $6.97 \mathrm{E}-05$ & $4.81 \mathrm{E}-03$ \\
\hline $1.14 \mathrm{E}-01$ & $0.00 \mathrm{E}+00$ & $4.05 \mathrm{E}-05$ & 7.40E-05 & 4.73E-03 \\
\hline 1.19E-01 & $0.00 \mathrm{E}+00$ & $4.03 \mathrm{E}-05$ & 7.83E-05 & $4.65 \mathrm{E}-03$ \\
\hline 1.19E-01 & $0.00 \mathrm{E}+00$ & 4.03E-05 & 7.87E-05 & 3.87E-04 \\
\hline $1.24 \mathrm{E}-01$ & $0.00 \mathrm{E}+00$ & $4.03 \mathrm{E}-05$ & $8.27 \mathrm{E}-05$ & $4.50 \mathrm{E}-03$ \\
\hline
\end{tabular}


$\mathrm{C}++$ program developed to calculate particles at each outlet is illustrated below and is based on the dimensions of the SSAW particle separator illustrated in Figure 5.

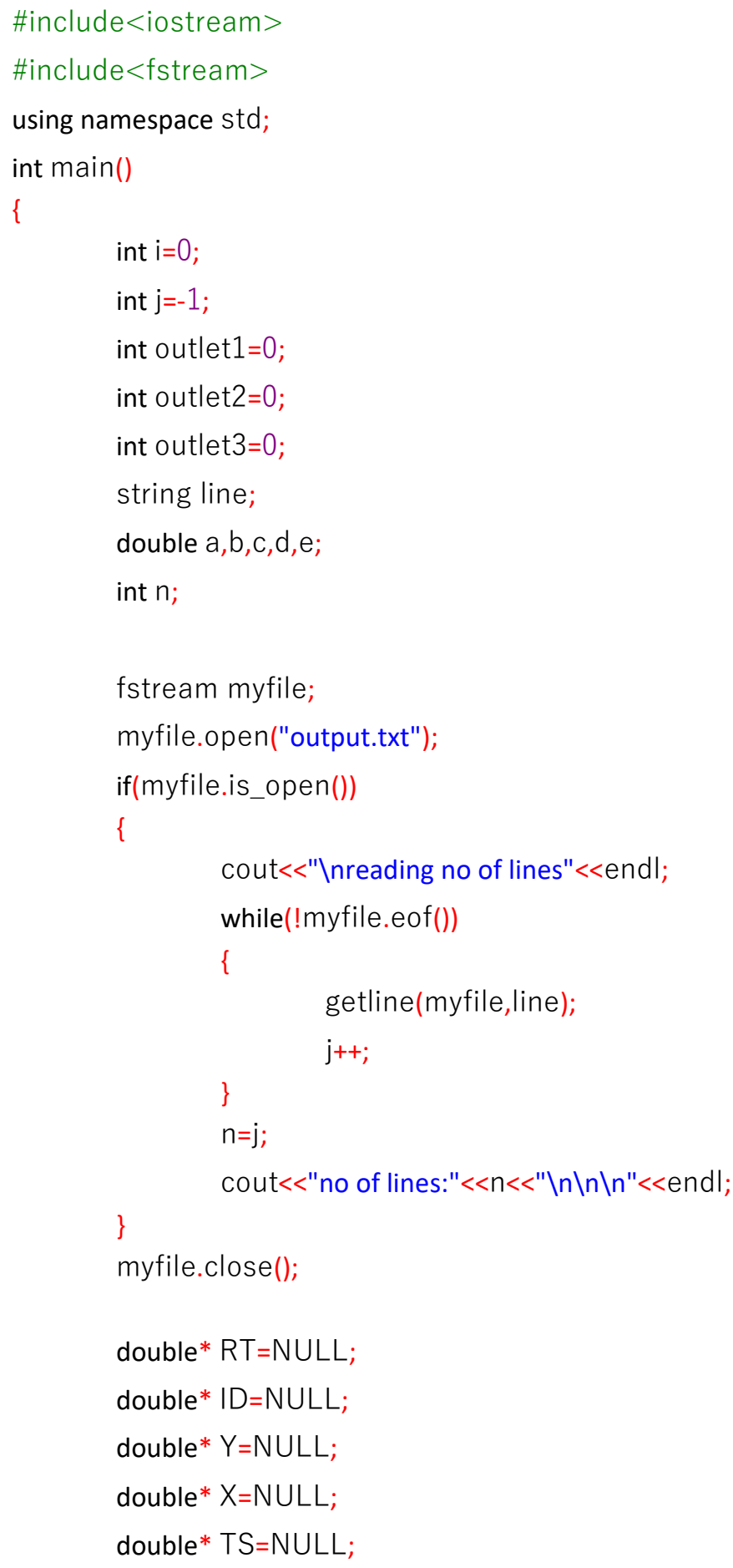




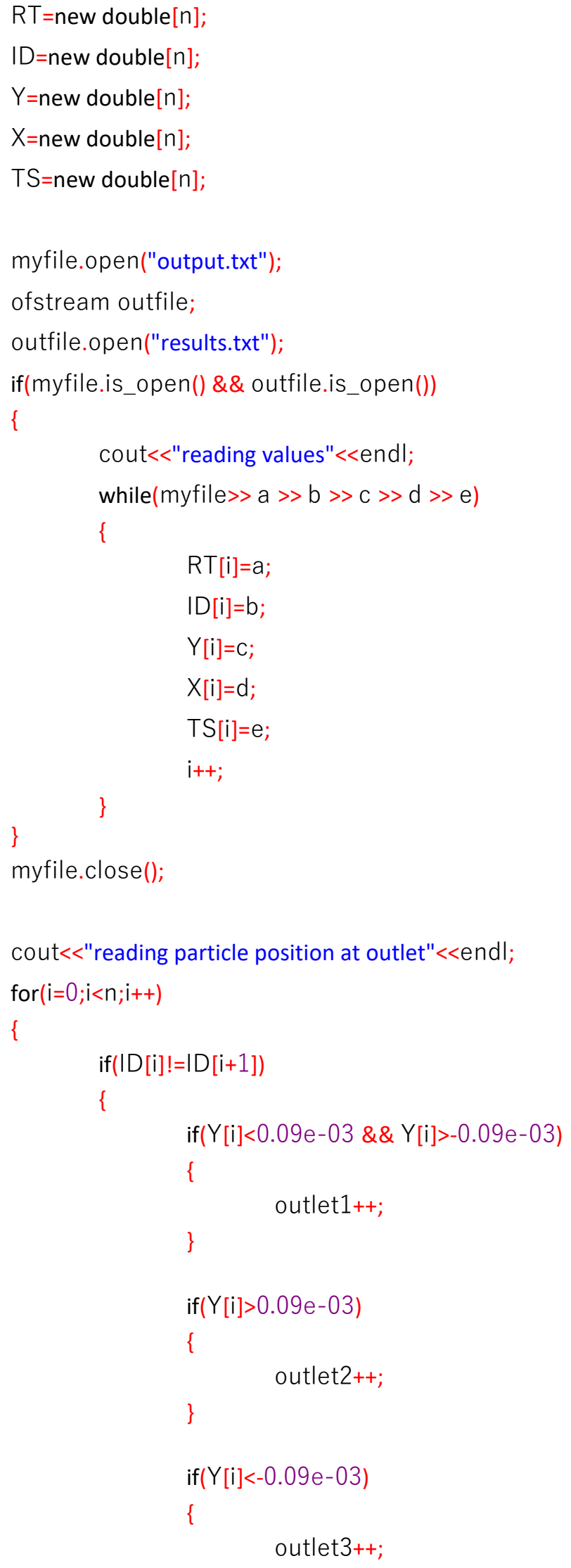




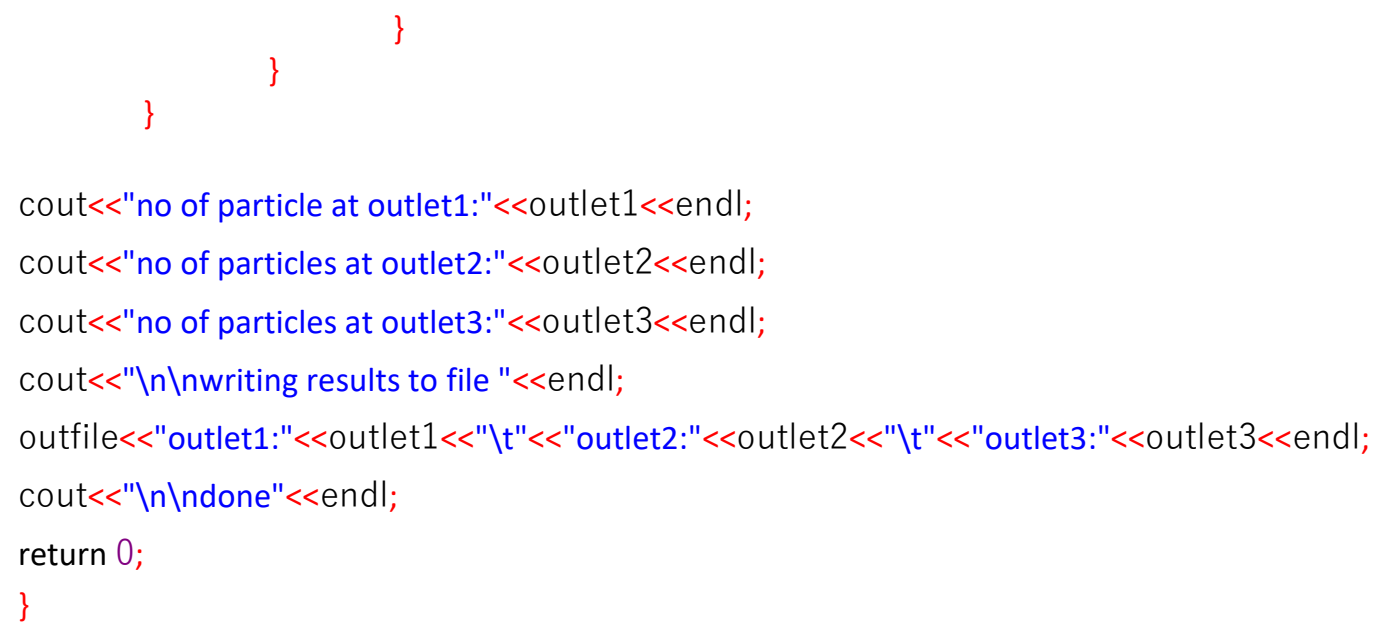

To obtain the number of particles at each outlet, the data obtained from the track history file is to be copied to the output.txt and upon running the code the results would be written to results.txt. 


\section{APPENDIX C: COPYRIGHT PERMISSIONS}

\section{The permission below is for the use of material in Chapter 2.}

$\equiv a x^{x} \quad$ |MDPI $\quad \log$ in

MDPI Open Access Information and Policy

All articles published by MDPI are made immediately available worldwide under an open access license. This means:

- everyone has free and unlimited access to the full-text of all articles published in MDPI journals;

- everyone is free to re-use the published material if proper accreditation/citation of the original publication is given;

- open access publication is supported by the authors' institutes or research funding agencies by payment of a comparatively low Article Processing Charge (APC) for accepted articles.

External Open Access Resources

MDPI is a ROMEO green publisher [- ROMEO is a database of Publishers' copyright and self-archiving policies hosted by the University of Nottingham 圂

Those who are new to the concept of open access might find the following websites or 'Open Access 101' video informative:

Wikipedia article on 'Open Access' (⿴囗大)

Peter Suber's 'Open Access Overview' (a)

Information Platform Open Access [in English [四, in German []

SHERPA's 'Authors and Open Access' 四

In accordance with major definitions of open access in scientific literature (namely the Budapest,

Berlin, and Bethesda declarations), MDPI defines open access by the following conditions:

- peer-reviewed literature is freely available without subscription or price barriers,

- literature is immediately released in open access format (no embargo period), and

- published material can be re-used without obtaining permission as long as a correct citation to

the original publication is given.

Until 2008, most articles published by MDPI contained the note: "๔) year by MDPI

(http://uww.mdpi.org). Reproduction is permitted for noncommercial purposes". During 2008, MDPI journals started to publish articles under the Creative Commons Attribution License 国 and are now using the latest version of the $\mathrm{CC}$ BY license, which grants authors the most extensive rights. All articles published by MDPI before and during 2008 should now be considered as having been released under the post-2008 Creative Commons Attribution License.

This means that all articles published in MDPI journals, including data, graphics, and supplements, can be linked from external sources, scanned by search engines, re-used by text mining applications or websites, blogs, etc. free of charge under the sole condition of proper accreditation of the source and original publisher. MDPI believes that open access publishing fosters the exchange of research results amongst scientists from different disciplines, thus facilitating interdisciplinary research. Open access publishing also provides access to research results to researchers worldwide, including those from developing countries, and to an interested general public. Although MDPI publishes all of its journals under the open access model, we believe that open access is an enriching part of the scholarly communication process that can and should co-exist with other forms of communication and publication, such as society-based publishing and conferencing activities.

Important Note: some articles (especially Reviews) may contain figures, tables or text taken from other publications, for which MDPI does not hold the copyright or the right to re-license the published material. Please note that you should inquire with the original copyright holder (usually the original publisher or authors), whether or not this material can be re-used. 


\section{The permission below is for the use of material in Chapter 3.}

\section{NNSYS}
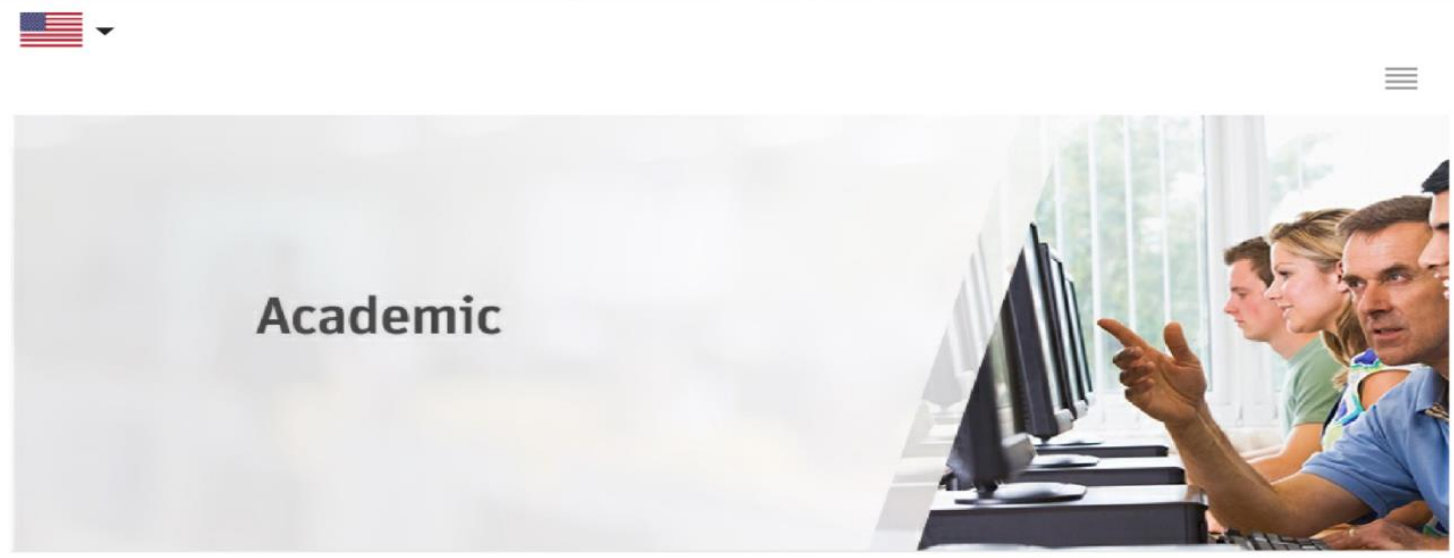

HOME / ACADEMIC / TERMS AND

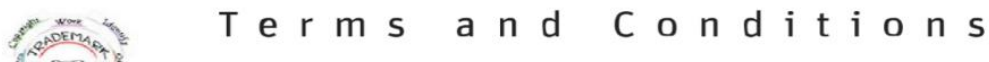

When writing a technical paper, white paper, article, thesis, presentation, book or web page, you may need to reference ANSYS or its products. In all cases, authors should work to ensure that the reference is specific and clear and that any interested reader will be able to easily find the referenced information. There are specific legal requirements that writers must adhere to as well. The guidelines below under Product Names, Fair Use and Copyright, and Trademarks can help authors get started. Refer to the linked documents for more detailed information.

Additionally, our ANSYS Academic product license terms are aligned with academic use. Please see Licensing and Terms of Use for a full explanation of how our Academic products can be used.

Learn More...

PRODUCT NAMES

FAIR USE AND COPYRIGHT

TRADEMARKS

LICENSING AND TERMS OF USE

Because the ANSYS portfolio contains a wide range of products, simply stating that you used "ANSYS" software does not help readers to accurately identify the product(s) and capabilities needed to better understand your work.

Product references should be accompanied by the release version. Refer to your product license form for the correct product name.

- Example product reference: ANSYS Academic Research Mechanical, Release 18.1

- Please include the product name in the paper/presentation abstract and add the product documentation as a reference whenever possible.

Documentation references should be accompanied by the relevant product name, release version, document book, chapter and page. Note that manuals, online help and other documentation accompanying the software are protected by copyright law and subject to nondisclosure provisions in your software license agreement. If you paraphrase or summarize documentation text in your own words, then you must cite the source of this information.

Example documentation citation: ANsys Academic Research Mechanical, Release 78.1, Help system, Coupled Field Analysis Guide, ANSYS, Inc.

General documentation citation: ANSYS ${ }^{\circ}$ [product name], release number, help system, [book and chapter reference name/numbers], ANSYS, Inc. Private communications (such as technical support responses) from ANSYS should not be cited. 
The permission below is for reproducing this thesis as the full published article in the

\section{Microsystem Technologies.}

$10 / 10 / 2018$

RightsLink Printable License

SPRINGER NATURE LICENSE

TERMS AND CONDITIONS

Oct 10,2018

This Agreement between Mr. shivaraman asoda ("You") and Springer Nature ("Springer Nature") consists of your license details and the terms and conditions provided by Springer Nature and Copyright Clearance Center.

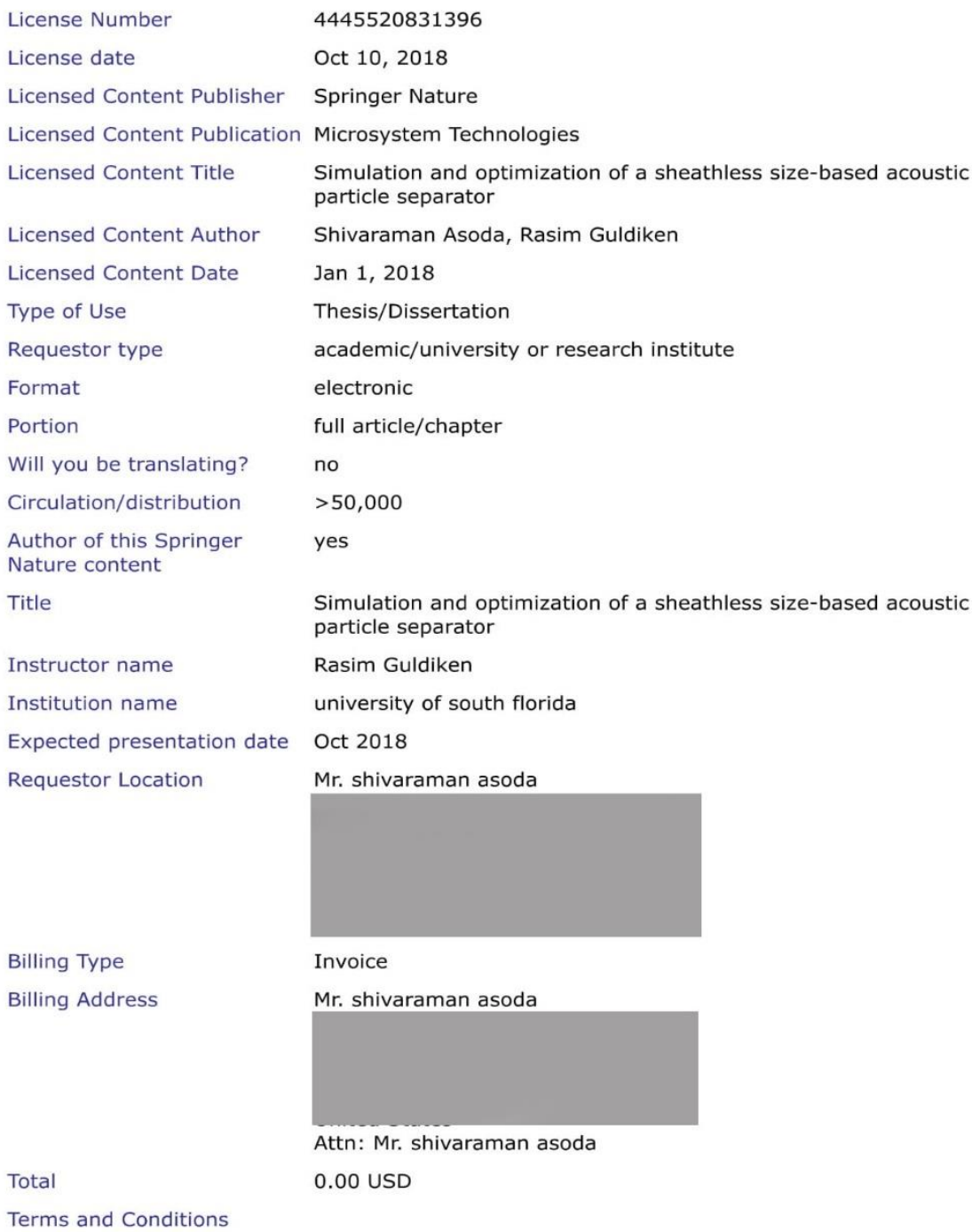

Billing Type Invoice

Billing Address

Mr. shivaraman asoda

Attn: Mr. shivaraman asoda

Total

0.00 USD

Terms and Conditions

Springer Nature Terms and Conditions for RightsLink Permissions

https://s100.copyright.com/CustomerAdmin/PLF.jsp?ref=6acd0896-0485-4408-a6ed-718671f52367 
Springer Nature Customer Service Centre GmbH (the Licensor) hereby grants you a non-exclusive, world-wide licence to reproduce the material and for the purpose and requirements specified in the attached copy of your order form, and for no other use, subject to the conditions below:

1. The Licensor warrants that it has, to the best of its knowledge, the rights to license reuse of this material. However, you should ensure that the material you are requesting is original to the Licensor and does not carry the copyright of another entity (as credited in the published version).

If the credit line on any part of the material you have requested indicates that it was reprinted or adapted with permission from another source, then you should also seek permission from that source to reuse the material.

2. Where print only permission has been granted for a fee, separate permission must be obtained for any additional electronic re-use.

3. Permission granted free of charge for material in print is also usually granted for any electronic version of that work, provided that the material is incidental to your work as a whole and that the electronic version is essentially equivalent to, or substitutes for, the print version.

4. A licence for 'post on a website' is valid for 12 months from the licence date. This licence does not cover use of full text articles on websites.

5. Where 'reuse in a dissertation/thesis' has been selected the following terms apply: Print rights of the final author's accepted manuscript (for clarity, NOT the published version) for up to 100 copies, electronic rights for use only on a personal website or institutional repository as defined by the Sherpa guideline (www.sherpa.ac.uk/romeo/).

6. Permission granted for books and journals is granted for the lifetime of the first edition and does not apply to second and subsequent editions (except where the first edition permission was granted free of charge or for signatories to the STM Permissions Guidelines http://www.stm-assoc.org/copyright-legal-affairs/permissions/permissions-guidelines/), and does not apply for editions in other languages unless additional translation rights have been granted separately in the licence.

7. Rights for additional components such as custom editions and derivatives require additional permission and may be subject to an additional fee. Please apply to Journalpermissions@springernature.com/bookpermissions@springernature.com for these rights.

8. The Licensor's permission must be acknowledged next to the licensed material in print. In electronic form, this acknowledgement must be visible at the same time as the figures/tables/illustrations or abstract, and must be hyperlinked to the journal/book's homepage. Our required acknowledgement format is in the Appendix below.

9. Use of the material for incidental promotional use, minor editing privileges (this does not include cropping, adapting, omitting material or any other changes that affect the meaning, intention or moral rights of the author) and copies for the disabled are permitted under this licence.

10. Minor adaptations of single figures (changes of format, colour and style) do not require the Licensor's approval. However, the adaptation should be credited as shown in Appendix below.

\section{Appendix - Acknowledgements:}

For Journal Content:

Reprinted by permission from [the Licensor]: [Journal Publisher (e.g. 
Nature/Springer/Palgrave)] [JOURNAL NAME] [REFERENCE CITATION (Article name, Author(s) Name), [COPYRIGHT] (year of publication)

For Advance Online Publication papers:

Reprinted by permission from [the Licensor]: [Journal Publisher (e.g. Nature/Springer/Palgrave)] [JOURNAL NAME] [REFERENCE CITATION

(Article name, Author(s) Name), [COPYRIGHT] (year of publication), advance online publication, day month year (doi: 10.1038/sj.[JOURNAL ACRONYM].)

For Adaptations/Translations:

Adapted/Translated by permission from [the Licensor]: [Journal Publisher (e.g. Nature/Springer/Palgrave)] [JOURNAL NAME] [REFERENCE CITATION

(Article name, Author(s) Name), [COPYRIGHT] (year of publication)

Note: For any republication from the British Journal of Cancer, the following credit line style applies:

Reprinted/adapted/translated by permission from [the Licensor]: on behalf of Cancer Research UK: : [Journal Publisher (e.g. Nature/Springer/Palgrave)] [JOURNAL NAME] [REFERENCE CITATION (Article name, Author(s) Name),

[COPYRIGHT] (year of publication)

For Advance Online Publication papers:

Reprinted by permission from The [the Licensor]: on behalf of Cancer Research UK: [Journal Publisher (e.g. Nature/Springer/Palgrave)] [JOURNAL NAME]

[REFERENCE CITATION (Article name, Author(s) Name), [COPYRIGHT] (year of publication), advance online publication, day month year (doi: 10.1038/sj.

[JOURNAL ACRONYM])

For Book content:

Reprinted/adapted by permission from [the Licensor]: [Book Publisher (e.g. Palgrave Macmillan, Springer etc) [Book Title] by [Book author(s)]

[COPYRIGHT] (year of publication)

Other Conditions:

Version 1.1

Questions? customercare@copyright.com or +1-855-239-3415 (toll free in the US) or +1-978-646-2777. 